\title{
Iron Oxide-Based Magneto-Optical Nanocomposites for In Vivo Biomedical Applications
}

\author{
Nisha Lamichhane ${ }^{1}\left(\mathbb{D}\right.$, Shalini Sharma ${ }^{2}$, Parul ${ }^{2}$, Anita Kamra Verma ${ }^{3}$, Indrajit Roy ${ }^{2}$ and Tapas Sen ${ }^{1, *}$ \\ 1 Nano-Biomaterials Research Group, School of Natural Sciences, University of Central Lancashire, \\ Preston PR1 2HE, UK; NLamichhane2@uclan.ac.uk \\ 2 Department of Chemistry, University of Delhi, Delhi 110007, India; shalinidu1990@gmail.com (S.S.); \\ singh.parul809@gmail.com (P.); indrajitroy11@gmail.com (I.R.) \\ 3 Nano Biotech Lab, Department of Zoology, Kirori Mal College, University of Delhi, Delhi 110007, India; \\ akverma@kmc.du.ac.in \\ * Correspondence: tsen@uclan.ac.uk; Tel.: +44-(0)1772894371
}

Citation: Lamichhane, N.; Sharma, S.; Parul; Verma, A.K.; Roy, I.; Sen, T. Iron Oxide-Based Magneto-Optical Nanocomposites for In Vivo Biomedical Applications. Biomedicines 2021, 9, 288. https://doi.org/ $10.3390 /$ biomedicines 9030288

Academic Editor: Shaker Mousa

Received: 12 February 2021

Accepted: 8 March 2021

Published: 12 March 2021

Publisher's Note: MDPI stays neutral with regard to jurisdictional claims in published maps and institutional affiliations.

Copyright: (c) 2021 by the authors. Licensee MDPI, Basel, Switzerland. This article is an open access article distributed under the terms and conditions of the Creative Commons Attribution (CC BY) license (https:/ / creativecommons.org/licenses/by/ $4.0 /)$.

\begin{abstract}
Iron oxide nanoparticles (IONPs) have played a pivotal role in the development of nanomedicine owing to their versatile functions at the nanoscale, which facilitates targeted delivery, high contrast imaging, and on-demand therapy. Some biomedical inadequacies of IONPs on their own, such as the poor resolution of IONP-based Magnetic Resonance Imaging (MRI), can be overcome by co-incorporating optical probes onto them, which can be either molecule- or nanoparticulate-based. Optical probe incorporated IONPs, together with two prominent non-ionizing radiation sources (i.e., magnetic field and light), enable a myriad of biomedical applications from early detection to targeted treatment of various diseases. In this context, many research articles are in the public domain on magneto-optical nanoparticles; discussed in detail are fabrication strategies for their application in the biomedical field; however, lacking is a comprehensive review on real-life applications in vivo, their toxicity, and the prospect of bench-to-bedside clinical studies. Therefore, in this review, we focused on selecting such important nanocomposites where IONPs become the magnetic component, conjugated with various types of optical probes; we clearly classified them into class 1 to class 6 categories and present only in vivo studies. In addition, we briefly discuss the potential toxicity of such nanocomposites and their respective challenges for clinical translations.
\end{abstract}

Keywords: iron oxide nanoparticles (IONPs); optical probes; magneto-optical; semiconductor; carbon quantum dots; up-conversion; plasmonic; theranostics; cancer; diagnostics; therapeutics

\section{Introduction}

Nanomaterials having the ability to simultaneously detect and cure various diseases is an emerging area of multidisciplinary research under nanobiotechnology due to their nanoscale dimensions [1]. Over the past decade, scientists have realized that multimodal nanoparticles can play an important role as theranostic agents in nanomedicine. Theranostics is a combination of diagnostic and therapeutic applications simultaneously using novel nanocomposites having multifunctional properties, thus, promising a 'paradigm shift' in the way medicine is practiced globally [2,3]. The ability to combine two or more complementary imaging modalities using carefully designed multimodal nanocomposites can help to generate comprehensive structural and functional diagnostic information [4]. The combination of therapeutic agents, especially those that can be externally activated by light or magnetic field and using them as a single nano-construct, facilitates not only diagnosis-driven targeted therapy but also real-time monitoring of therapeutic action at disease sites [5]. Substantial research has already been carried out on the applications of nanoparticles in medicine and led to the identification of certain positive trends that are likely to dictate the future roadmap on nanomedicine [6]. In particular, iron oxide nanoparticles (IONPs) have emerged as principal candidates due to their minimal toxicity 
in cellular systems and multimodal functionality such as superparamagnetism, localized heating under alternative magnetic fields (AMF), and magnetic resonance imaging (MRI) contrast enhancement [7-9]. In addition, IONPs have been utilized as photothermal agents for photothermal therapy (PTT) using light [10]. Similarly, the use of IONPs as a tracer for magnetic particle imaging (MPI) is being explored for producing three-dimensional images of IONPs distribution in tissues [11]. All these properties have been successfully utilized for unique diagnostic, targeting, and therapeutic purposes. For example, the ability to concentrate systemically administered iron-oxide nanoparticles into tumor sites using an external magnetic field is an excellent avenue for actively targeted delivery of minimally modified versions. MRI using $\mathrm{T}_{2}$ contrast enhancement of IONPs is widely applied in pre-clinical settings. AMF directed hyperthermia using these nanoparticles can render localized heating to the tumor site with minimum off-target effects as a potential therapeutic route. The ease of synthesis, surface modification, storage, handling, and transport of these nanoparticles are additional benefits that would pave the way for their successful clinical translation.

Similarly, organic dyes such as Rhodamine 6G (R6G) have been widely used as a fluorescence marker for monitoring the distribution of biological molecules into the target sites by using fluorescence spectroscopy [12]. However, there are drawbacks to using organic dyes, such as their low quantum yield and rapid photo-bleaching. This has resulted in the development of optical nanoparticles such as quantum dots with high quantum yield and photo-stability [12]. In addition, they can be excited at any wavelength, unlike optical dyes, and provide sharp and bright emission light of various colors by carefully tuning their sizes ranging from $2 \mathrm{~nm}$ to $10 \mathrm{~nm}$. However, due to their toxicity, several other optical nanoparticles such as carbon/graphene dots, plasmonic and up-conversion nanophosphors have recently emerged. These optical probes are unique biological tags for monitoring their distribution in cellular systems by simple spectrophotometry as an imaging platform. In addition, many of them can also produce localized heat (hyperthermia) by activating them using a certain wavelength of laser light, hence can be utilized as therapeutic agents.

A combination of optical probes with IONPs can further enhance the repertoire of their biomedical applications. They also offer a myriad choice of nanomaterials, which can be selected for a specific biomedical application as diagnostic and therapeutic tools. Several review articles can be found that have chronicled separately either optical or magnetic nanostructures in terms of their synthesis, characterization, and biomedical applications. However, a comprehensive review of combining multimodal functionality in a single nanoconstruct and their application in real-life scenarios such as in vivo study, their toxicity, and status of clinical trials could immensely help nanomedicine researchers, and is currently lacking in the literature. Therefore, it is the first attempt to compile a review article with a focus on multimodal nanomaterials, which contain at least one optical probe in conjugation with IONPs (as magnetic component) for in vivo applications only. We have classified all possible optical probes in conjugation with IONPs into various classes and identified them as (i) molecule-based agents (e.g., dyes, photosensitizers), and (ii) nanomaterials. Nanomaterials include semiconductors (quantum dots), metals (plasmonic nanomaterials, metal nanoclusters), rare-earth-doped matrices (nanophosphors), dye-doped optically transparent matrices (e.g., dye/silica), and various forms of carbon such as graphene nanoparticles, nanotubes, and carbon dots. Finally, we have summarized their toxicity in in vivo biomedical applications and the current status of their clinical trial as magnetooptical nano-constructs. Figure 1 provides a schematic representation of various classes of magneto-optical nanomaterials described in this review and their multi-modality as theranostic agents for in vivo biomedical applications. 


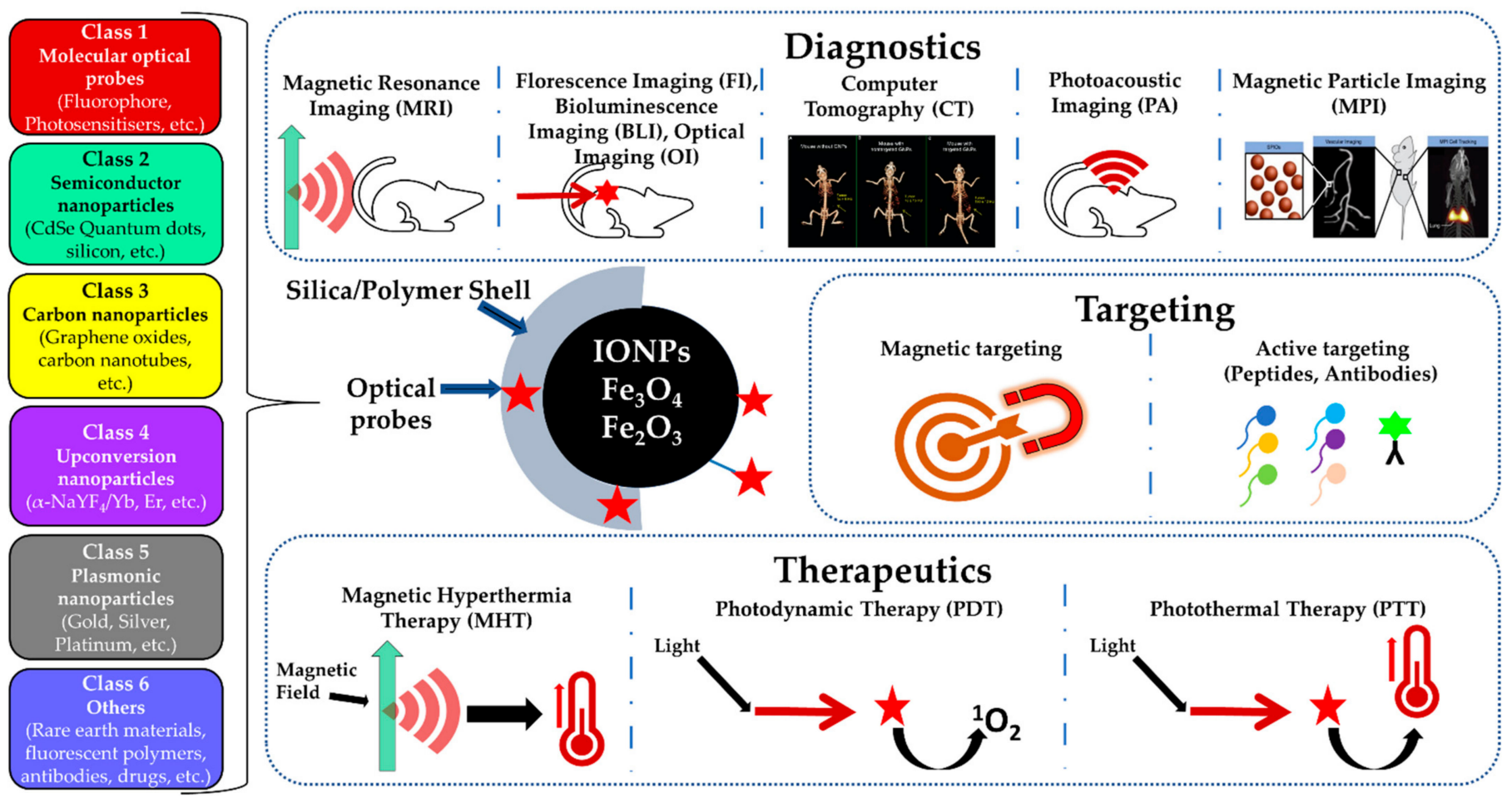

Figure 1. Schematic representation depicting iron oxide-optical probe conjugated nanocomposites for various in vivo biomedical applications. Different colors in the left represent different classes of optical probes. Green arrow indicates the magnetic field, red waves indicate the radiation, red stars indicate optical probe and thermometer symbols indicate temperature elevation due to heating.

\section{Various Classes of Magneto-Optical Nanocomposites}

\subsection{Class 1: Molecular Optical Probe-Iron Oxide Nanocomposites}

Organic molecule-based optical probes are divided into two categories such as fluorophores as a diagnostic tool for optical imaging and photosensitizers as therapeutic tools for photodynamic therapy (PDT) and photothermal therapy (PTT). These molecular probes can be easily integrated on the surface of IONPs, either via direct conjugation or by incorporation/entrapment within a transparent micelle (lipid or polymeric) or silica shell upon the IONPs core. In each case, it is essential that the optical properties of the optical probes are not only preserved but also enhanced for some applications.

Optical imaging using organic molecules as fluorescent probes has been in practice for a long time now. Traditional organic fluorophores, such as rhodamine and fluorescein, have several drawbacks, such as limited optical range and a tendency to photo-bleach rapidly. Therefore, they have been primarily used in in vitro applications, such as labeling intracellular organelles. The advancement of new fluorophores and their properties, such as their emission in the near infra-red (NIR) range and resistance to photobleaching, aided by concurrent development in in vivo optical imaging techniques, has created huge interest in the nanomedicine research community. Currently, several such fluorophores are actively used not only in pre-clinical optical imaging investigations but also in human intraoperative procedures with some limitations, i.e., active targeting [13-15]. Therefore, their combination with IONPs further bolsters their versatility, which includes real-time monitoring of in vivo pharmacodynamics and bio-distribution of nanoparticles, in vivo microenvironment biosensing, analysis of excretion, and their potential long-term fate inside the body using multimodal imaging, etc. [16,17].

Pioneering work by Ralph Weissleder's group paved the way for the development of iron-oxide nanoparticle-fluorophore conjugates for biomedical applications [16-20]. In their first report, they used a formulation of cross-linked iron oxide (CLIO) nanoparticles conjugated with the NIR dye indocyanine Cy5.5 to demonstrate dual-modality (combining MRI 
and optical imaging) for the visualization of axillary and brachial lymph nodes in vivo [16]. They further went on to demonstrate a series of exciting in vivo applications of the CLIO nanoparticles, which includes image-guided surgery of glioma (brain tumors) in rats [17], imaging of inflammation of pancreatic islets in diabetic mice [18], and atherosclerosis [19], and monitoring cardiomyocyte apoptosis in mice [20].

Several researchers have explored the possibility of formulating lipophilic IONPs within block-copolymer micelles, along with co-entrapping molecular fluorophores within the micellar shells. Vinod Labhasetwar's group used Pluronic block copolymer-micelles to co-entrap the hydrophobic NIR fluorophores (SDB5700, SDA5177, SDA2826, SDA6825, and SDB5491) along with IONPs [21]. Using an external magnetic field for guidance, these nanoparticles were highly efficient in targeting tumor sites as compared to passive tumor targeting. Micelles of other amphiphilic co-polymers, such as poly(isobutylene-alt-maleic anhydride) and 1,2-Distearoyl-sn-glycero-3-phosphoethanol amine- $\mathrm{N}$-amino(polyethylene glycol) (DSPE-PEG-NH $\mathrm{N}_{2}$ ), were used by other groups to stabilize IONPs and to co-entrap NIR fluorophores for tumor-targeted multimodality imaging and bio-distribution analysis [22,23].

Glycol-chitosan nanoparticles entrapped several ferrimagnetic iron-oxide nanocubes (IONCs) with surface-conjugated NIR fluorophore Cy5.5 and a tumor-targeting peptide [24]. The clustering of IONCs has led to enhanced contrast enhancement in MRI studies. Combined near-infrared fluorescence (NIRF) imaging and MRI demonstrated the detection of tumors as small as $5 \mathrm{~mm}$ in diameter in mice (Figure 2). In another report, breast cancer screening in mice was executed using four different imaging modalities such as X-ray Computed Tomography (CT), MRI, and NIR optical and dual-energy mammography [25]. In this study, the authors demonstrated the importance of iron oxide-based 'all-in-one nanoparticles' when combined with NIR fluorophore DiR and silver sulfide nanoparticles $\left(\mathrm{Ag}_{2} \mathrm{~S}-\mathrm{NP}\right)$.
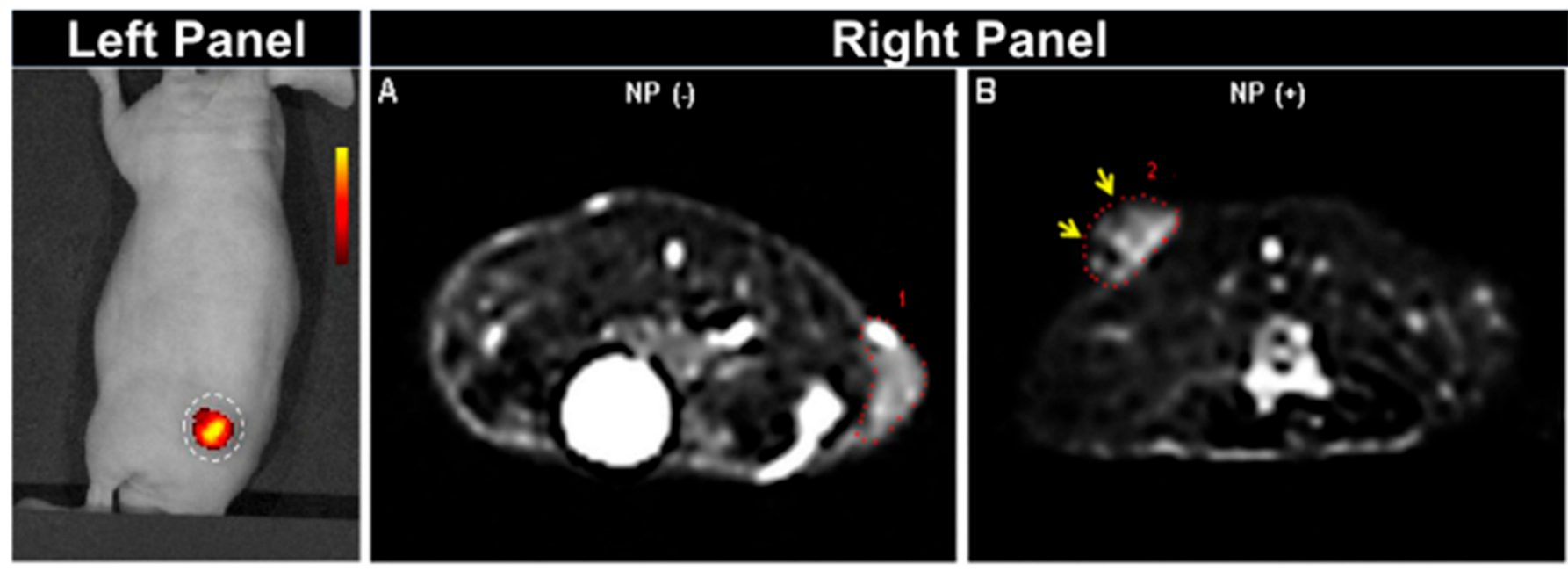

Figure 2. Different imaging modalities on athymic mice demonstrating tumor accumulation of nanocomposites after $24 \mathrm{~h}$ of injection. (Left Panel): In vivo NIRF imaging showing fluorescent tumor site, (Right Panel): 3T MRI. Red dotted lines 1 and 2 show the edge of the tumor before (A) and after (B) nanocomposites administration. Reprinted with permission from ref. [24]. Open Access Creative common.

In another study using Cy5.5 and IONPs, MPI modality was combined with MRI and NIRF imaging to improve in vivo screening [26]. The monodispersed carboxylated IONPs were conjugated with - $\mathrm{NH}_{2}$ or -FMOC end- poly-ethylene-glycols $\left(\mathrm{NH}_{2}-\mathrm{PEG}-\mathrm{NH}_{2}\right.$ and $\mathrm{NH}_{2}$-PEG FMOC) via amide bonding and clustered nanocomposite formed after labeling with Cy5.5. Figure 3 shows the accumulation of nanoparticles in the liver and spleen through three different complementary imaging modalities using MPI, NIRF, and MRI. The accumulation of nanocomposites on these tissues was attributed to the dominance of Kupffer cells and splenic macrophages in the liver and spleen, respectively. Each of 
the modalities reveals specific information about the fate of nanocomposites, while their combination could provide sensitivity on their tracking for more precise in vivo screening.
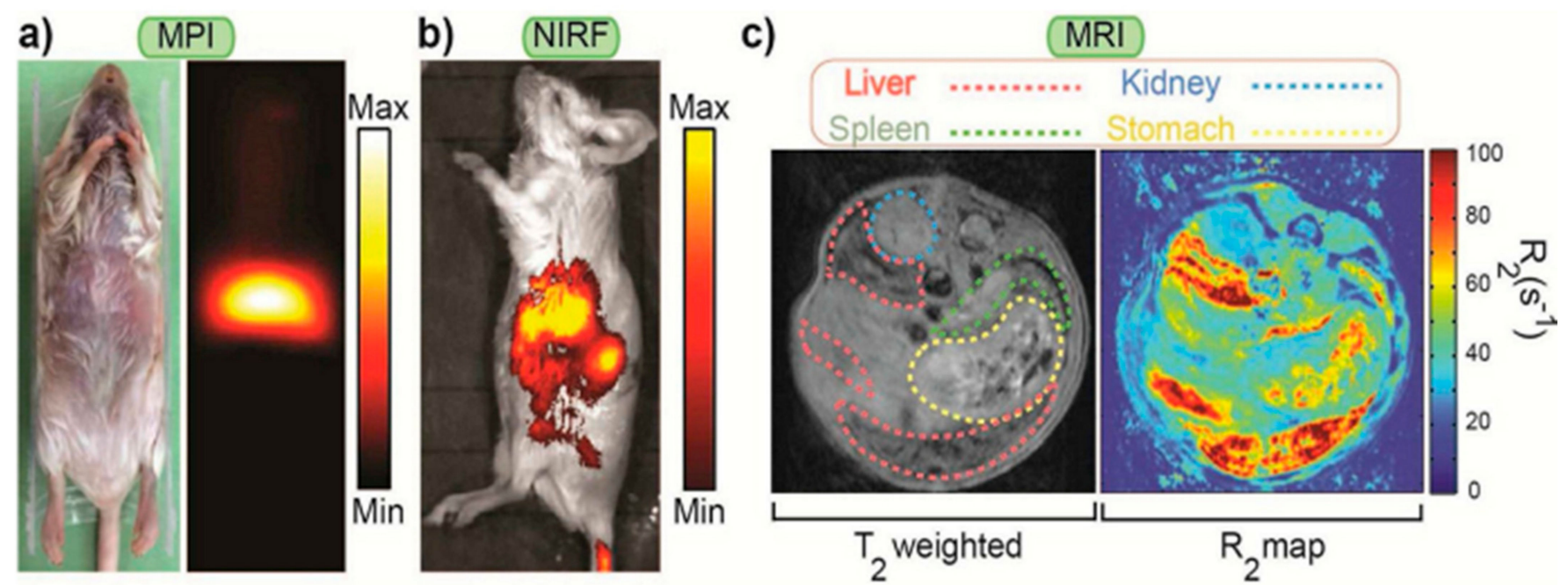

Figure 3. Complementary imaging modalities (a) colorized magnetic particle imaging (MPI) (b) near-infrared fluorescence (NIRF) and (c) MRI T 2 weighted and colorized $\mathrm{R}_{2}$ images $72 \mathrm{~h}$ after injection of nanoparticles (NPs) functionalized with $\mathrm{NH}_{2}$-PEG-FMOC (100 $\left.\mu \mathrm{L}, 1 \mathrm{mg} \mathrm{Fe} / \mathrm{mL}\right)$. Reprinted with permission from ref. [26]. Copyright 2015 Elsevier.

Non-invasive and early detection of amyloid- $\beta(A \beta)$ plaques in the brain is critical for the prevention of Alzheimer's disease (AD). IONPs were combined with carbazolebased cyanine NIR fluorophores for successful delivery across the blood-brain barrier and ultrasensitive imaging of $\mathrm{A} \beta$ plaques in vivo in an APP/PS1 transgenic mice model [27]. In another report, Jansen and co-workers showed robust in vivo targeting of orthopedic implants aided by an externally applied magnetic field using fluorescent probes embedded core-shell magnetic (silica shell with IONP core) nanoparticles [28].

Another important class of molecule-based optical probes is photosensitizers (PSs), which upon excitation by visible-NIR light produces reactive oxygen species (ROS) through intermediate processes [29]. These macrocyclic molecules include chlorins, phthalocyanines, pyropheophorbides, photofrin, etc. [30,31]. Usually, PSs have higher excited state lifetimes, which allows them to undergo intersystem crossing into a triplet state, whereby they interact with either molecular oxygen to produce singlet oxygen or with nearby biomolecules to produce other ROS species. The selective destruction of targeted diseased cells and tissues by the produced ROS upon photoexcitation of PSs is known as photodynamic therapy (PDT). A PS molecule can be incorporated with IONPs using similar strategies as fluorophores, and their combination can lead to several exciting applications such as magnetically targeting along with MRI-guided PDT, combination therapy involving PDT, and Magnetic Hyperthermia Therapy (MHT) in the presence of an AMF.

In 2005, Raoul Kopelman's group reported the co-incorporation of IONPs and the commercial photosensitizer "Photofrin" within polyacrylamide (PAA) nanoparticles containing surface conjugated F3 peptide [32]. Such magneto-optical nanocomposites used for $\mathrm{T}_{2}$ MRI contrasting efficiently imaged 9L glioma tumors orthotopically implanted in mouse brains. Subsequent laser light irradiation to the tumor led to a robust PDT effect and overall enhancement in the survival rate of tumor-bearing mice. This was followed by several other demonstrations of MRI-guided PDT. Sun et al. in 2009 used the biocompatible polysaccharide chitosan-coated formulation of IONPs combined with the porphyrin derivative as PS to study MRI and PDT in colon cancer in vivo [33]. Another group reported the use of functionalized $\mathrm{Fe}_{3} \mathrm{O}_{4}$ nanoparticles in combination with the PS chlorin e6 (Ce6, $\lambda_{\text {ex }} \sim 645 \mathrm{~nm}$ ) and PEG2K, and successfully demonstrated MRI and PDT effect in MGC-803 gastric cancer in vivo [34]. 
Combining IONPs with PS has led to a synergistic effect when applied in dual therapy involving MHT and PDT. Claire Wilhelm's group co-encapsulated $\mathrm{Fe}_{3} \mathrm{O}_{4}$ nanoparticles and the PS Temoporphin (m-THPC: 5,10,15,20-Tetra(m-hydroxyphenyl) chlorin) within liposomes and injected in tumor-bearing mice for combination therapy [35]. This was carried out by exposure of the tumor area either with an AMF $(30 \mathrm{mT}, 111 \mathrm{kHz})$ or laser irradiation $(100 \mathrm{~mW})$, alone or in combination. Complete elimination of the tumor was observed in mice undergoing combination therapy, whereas mice undergoing MHT or PDT alone showed only a partial therapeutic effect. Another example of the combination of MHT and PDT in vivo was demonstrated using $10 \mathrm{~nm}$ superparamagnetic $\mathrm{Fe}_{3} \mathrm{O}_{4}$ nanoparticles combined with the photosensitizer pheophorbide a [36].

In addition to PDT, certain PSs (e.g., Indocyanine green) have been utilized as probes for PTT as they produce heat upon excitation by visible-NIR light. In combination with IONPs the PTT effect of such PSs can be accompanied with other modalities for therapeutic (PDT and MHT) and diagnostics (NIRF imaging, MRI, and thermal imaging) purposes. In a study involving ICG loaded IONPs, the nanocomposites were injected into $4 \mathrm{~T} 1$ tumorbearing mice, and a real-time temperature increase to $47.3^{\circ} \mathrm{C}$ was observed under NIR laser irradiation (wavelength: $808 \mathrm{~nm}$, power density: $2 \mathrm{~W} / \mathrm{cm}^{2}$ ), for $5 \mathrm{~min}$ [37]. The thermal imaging data complemented the MRI and NIRF imaging verifying the accumulation of nanocomposites at the tumor site.

Recently, we have comprehensively reviewed class 1 molecular optical probes with IONPs for in vivo biomedical applications [38]. In the current review, we have covered selected examples on class 1 optical probes and explored fully classes 2 to 6 in combination with IONPs for in vivo biomedical applications.

\subsection{Class 2: Semiconductor Nanoparticles-Iron Oxide Nanocomposites}

Despite several recent advancements using molecular fluorescent probes for diagnostic purposes, they still suffer from photobleaching and quenching in in vivo studies, which limits their applications. Narrow absorption and broad emission spectra of organic fluorophore pose several practical challenges such as the requirement of specific light sources for excitation, the tendency for reabsorption/quenching by neighboring molecules, etc., for routine diagnostic applications. To overcome such limitations, semiconductor nanoparticles such as quantum dots have emerged as new-generation optical probes with broadband excitation and narrow emission spectra, as well as resistance to photobleaching [39]. Such quantum dots belonging to different classes of semiconductors, such as Groups II-VI, III-V, and IV (elements in the periodic table), and their combinations have been used for biomedical applications.

The above strategy was first applied by Shi et al. in 2009, utilizing quantum dots (QDs) immobilized $\mathrm{Fe}_{3} \mathrm{O}_{4}$ containing polystyrene nanospheres for simultaneous in vivo imaging and local MHT [40]. The selected QDs, with an emission wavelength of $800 \mathrm{~nm}$ having CdSeTe core and ZnS shell covalently functionalized with PEG, were immobilized on magnetic nanospheres by EDC: NHS (1-ethyl-3-(3-dimethylaminopropyl) carbodiimide/ $\mathrm{N}$ hydroxy succinimide) coupling and electrostatic adsorption. The nanoparticles, when administered to nude mice, provided a significant increase in fluorescence (excitation: $725 \mathrm{~nm}$, emission: $790 \mathrm{~nm}$ ) within one day after the injection. Additionally, the magnetic hysteresis showed the superparamagnetic properties of the nanoparticles, which upon application of $\mathrm{AMF}$, increased the temperature to $52^{\circ} \mathrm{C}$ within $30 \mathrm{~min}$.

Similarly, another magneto-optical nanoparticle with a core-shell structure was synthesized by co-assembling CdSe-CdS core-shell quantum dots with $\mathrm{Fe}_{3} \mathrm{O}_{4}$ [41]. The resultant core-shell nanoparticles were further coated with a thin layer of silica offering uniform and tunable sizes, high magnetic plus fluorophore content loading, high colloidal stability, and biocompatibility. After functionalization with poly(vinylpyrrolidone) (PVP) ethylene glycol (EG), the functionalized nanoparticles were observed to be spherical in morphology with an average diameter of $120 \mathrm{~nm}$ and were used in vivo multi-photon and MRI study. The nanoparticles were intravenously injected into mice bearing brain metastasis of a murine 
mammary carcinoma (MCaIV). Due to the high degree of aggregation of core MNPs in the resultant magneto-optical nanocomposite, the $\mathrm{T}_{2}$ relaxivity was $402.7 \mathrm{mM}^{-1} \mathrm{~s}^{-1}$, and was nearly 6.2 times larger than that of individual IONPs. A study using a combination of multiphoton and MRI revealed the accumulation of nanoparticles in the tumor region.

Cui and coworkers have established some pioneering research on the early identification of gastric cancer cells using magneto-optical nanoparticles of class 2 types [42,43]. In their early study in 2011, the group synthesized a fluorescent magnetic nanoparticle (FMNPs) composed of a silica-wrapped CdTe and IONPs of a size of around $50 \mathrm{~nm}$ and an attached anti-BRCAA1 antibody [42]. It was reported that BRCAA1 proteins are overexpressed in almost $65 \%$ of clinical specimens of gastric cancer tissues making it a suitable targeting molecule. In addition, the effect of different functional groups during the conjugation of anti-BRCAA1 antibodies on the surface of silica has been studied extensively. The conjugation efficiency of FMNPs with - $\mathrm{COOH}$ was found to be better than other functional groups. The nanoparticles were injected into nude mice with MGC-803 gastric cancer cells and studied for both optical imaging and MRI. The highest fluorescent signals were detected on the tumor site after $6 \mathrm{~h}$ of injection. The anti-BRCAA1-FMNPs nanoprobes preferentially accumulated in the tumor tissues, proven by MRI after $12 \mathrm{~h}$ of injection. Later, the same group utilized amino-modified silica-coated-FMNPs and labeled mesenchymal stem cells (MSCs) for magnetically targeted imaging and MHT in an in vivo gastric cancer model [43]. The MSCs labeled FMNPs showed fluorescent signals even after seven and 14 days of injection. The bio-distribution studies showed the nanoparticles accumulated only at the tumor site, as no specific fluorescent signal was detected in other major organs, indicating its' specificity towards the tumor sites. To evaluate the effect of hyperthermia in the mice model, an AMF (Frequency: $63 \mathrm{kHz}$ and Field: $7 \mathrm{kA} / \mathrm{m}$ ) was applied for 4 min once every week for the period of one month. The inhibition of tumor growth (in volume) was clearly visible when MSC labeled FMNPs were injected in the mice following MHT. The group further analyzed the chemokine receptors' expression levels in MSCs to investigate the mechanism of migration of MSC labeled nanoparticles on the gastric cancer cells in vivo. A concrete mechanism of MSC targeting was not possible; however, the study projected an increase in CXCL12-CXCR4 and CCL19-CCR7 by flow cytometry analysis.

Another study was carried on cyclic arginine-glycine-aspartate (cRGD)-conjugated magnetic-fluorescent (cRGD-MF) liposomes containing CdSe QDs as magneto-optical nanocomposite for targeted dual-modality imaging of bone metastasis from prostate cancer [44]. Hydrophilic IONPs along with hydrophobic CdSe QDs were encapsulated into liposomes with additional DSPE-PEG/DSPE-PEG-amines. cRGDyk (cyclic arginineglycine-aspartic acid-tyrosine-lysine peptide) and the resultant nanocomposites were further conjugated with distal ends of DSPE-PEG-amines. The final nanocomposites were reported to be spherical in morphology with a diameter of $\sim 120 \mathrm{~nm}$. The fluorescence intensity of the cRGD-MF was lower than that of CdSe QDs alone. The nanocomposites were studied for in vivo MRI and fluorescence imaging using a mice model of bone metastasis from prostate cancer by intra-tibial injection of RM-1 cells. When using a dose containing $15 \mathrm{mg}$ of liposomes per kilogram body weight injected via tail vein, a strong MRI signal was achieved in the cRGD-MF liposomes compared with the unconjugated MF liposomes, as shown in Figure 4 (left panel). Similarly, in in vivo fluorescent imaging study, the cRGD-MF liposomes nanocomposites nicely accumulated on the tumor region, resulting in better signal enhancement compared to the unconjugated liposomes, as shown in Figure 4 (right panel).

\subsection{Class 3: Carbon-Based Nanoparticles-Iron Oxide Nanocomposites}

Carbon-based nanoparticles, including carbon nanotubes (CNTs), carbon quantum/nanodots (CQDs), and graphene oxides (GO), have been exploited in in vivo biomedical applications due to their optical properties. CNTs are cylindrical structured carbon molecules mainly classified as single-walled carbon nanotubes (SWCNT), doublewalled carbon nanotubes (DWCNTs), and multi-walled carbon nanotubes (MWCNTs) 
based on the number of graphitic layers. CNTs in combination with IONPs have recently been applied for both diagnosis as enhanced hybrid MRI contrast agents and therapeutic by selective targeting, drug delivery, and MHT [45].
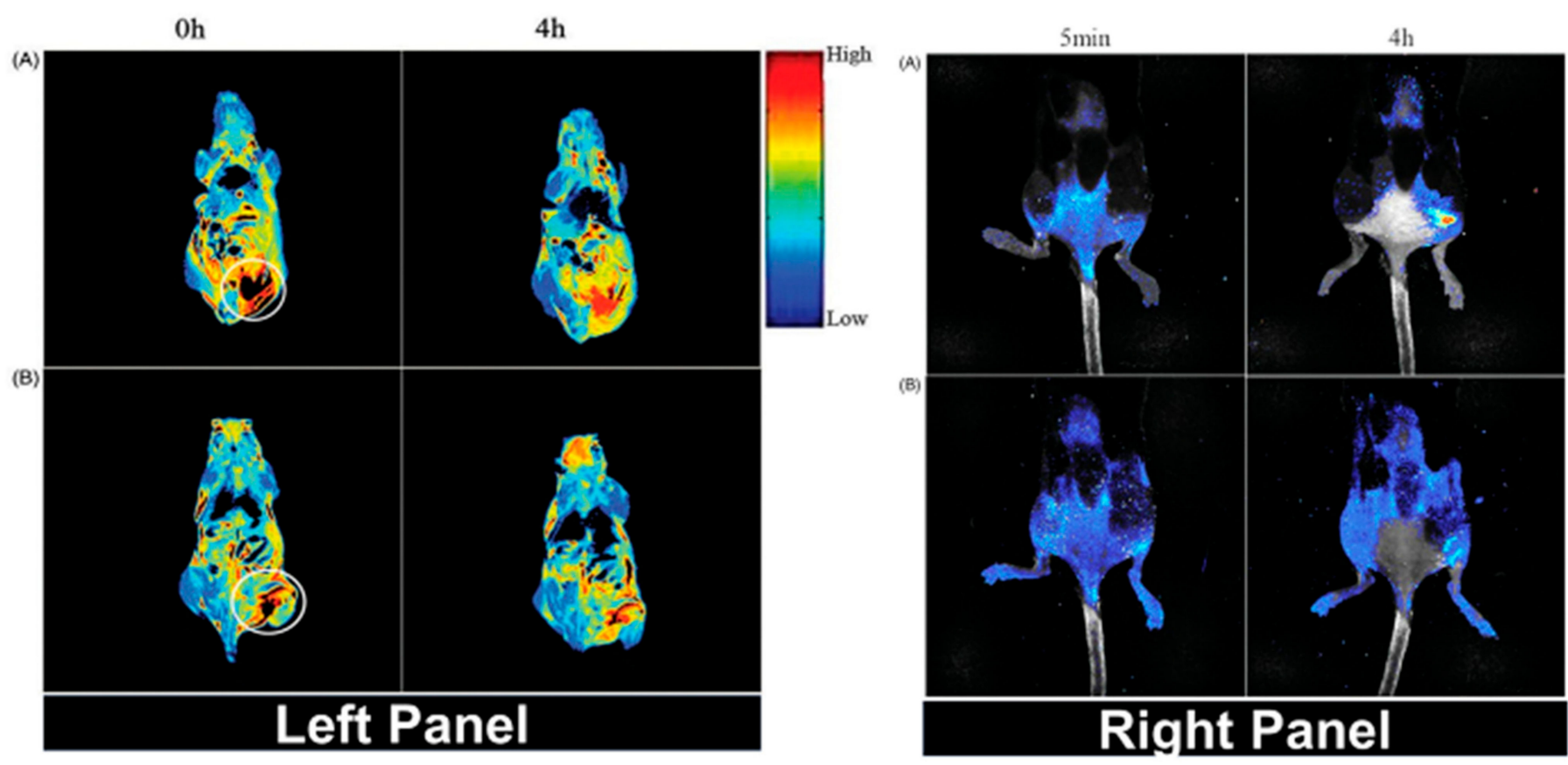

Figure 4. Whole-body $\mathrm{T}_{2}$ images in pseudo-color mode (Left Panel) and fluorescent images (Right Panel) in a bone metastasis model at different time intervals of injection of (A) cyclic arginine-glycine-aspartate (cRGD)-conjugated magnetic-fluorescent (MF) liposomes and (B) unconjugated MF-liposomes. White circles in the left panel represent tumor sites. Reprinted with permission from ref. [44]. Copyright 2015 Taylor \& Francis.

Doxorubicin-loaded SWCNTs tagged with IONPs followed by conjugation with Endoglin/CD105 antibodies have been used for active targeting and offering a theranostic approach with bioluminescence imaging (BLI) and MRI [46]. Delivering doxorubicin using IONPs-SWCNTs nanocomposites as drug delivery vehicles can reduce the toxicity and unnecessary side effects associated with nonselective bio-distribution. In their experiment, synthesized IONPs-SWCNTs were used for the conjugation with Endoglin/CD105 antibody through EDC: NHS coupling [46]. Doxorubicin binding was performed by physicochemical interaction with the magnetic CD105-conjugated SWCNTs. When injected intravenously on a tumor model of female Balb/c mice with 4T1-Luc2 cancerous cells, a significant decrease in primary tumor size was observed. Inhibition of tumor metastasis in the lungs following the injection of iron-tagged SWCNTs-Dox was also observed through BLI. $\mathrm{T}_{2}$ MRI contrasting also confirmed the enhancement in magnetic targeting towards the tumor site due to the progressive decrease in signal intensity in a time-dependent manner. Furthermore, to detect the treatment-induced changes in the tumor site, a diffusion-weighted MRI (DW-MRI) experiment was carried out where an apparent diffusion coefficient (ADC) value was directly related to the killing efficiency of tumor cells. It was observed that the magnetically targeted IONPs-SWCNTs produced significant changes in ADC values between 7-14 days after the injection, suggesting its efficiency in cancer treatment as a noninvasive imaging biomarker.

CQDs conjugated with IONPs have also been utilized for biomedical applications and are potential candidates for next-generation optical imaging owing to their excellent luminescence and photostability [47]. The release of free radicals from the magnetic CQDs accounts for most of its intrinsic cytotoxicity. Due to the release of free radicals on the bloodstream, bare IONPs can be unsafe for clinical translation, therefore, realizing the importance of surface coatings. $\gamma$-PGA is a natural anionic biopolymer that can be used 
as carbon and nitrogen precursors, simultaneously providing good water solubility and biocompatibility to inorganic nanocomposites [48]. The $\gamma$-PGA was used as a precursor and as a stabilizer to synthesize stable nitrogen-doped CQD-IONPs and labeled as C- $\mathrm{Fe}_{3} \mathrm{O}_{4}$ QDs with tri-modal in vivo bioimaging possibilities such as MRI, CT, and fluorescence (FL) imaging, as shown in Figure 5 [48]. The nanocomposites showed a transverse relaxation rate $\left(\mathrm{r}_{2}\right)$ of $154.10 \mathrm{~mm}^{-1} \mathrm{~s}^{-1}$ and an observable X-ray attenuation effect for CT imaging mode when injected in HeLa tumor-bearing nude mice. For evaluating the FL imaging, mice were positioned in a CRI Maestro in vivo fluorescence imaging system (excitation: 420 and $440 \mathrm{~nm}$; emission: 520 and $570 \mathrm{~nm}$ ). A strong FL signal was observed at the tumor site and bladder when excited at $420 \mathrm{~nm}$ (see Figure 5). In a bio-distribution study, the organs were excised after $24 \mathrm{~h}$ of injection, showing a significantly higher number of nanocomposites in the tumor site and in the kidney, as evaluated by inductively coupled plasma mass spectrometry (ICP-MS).

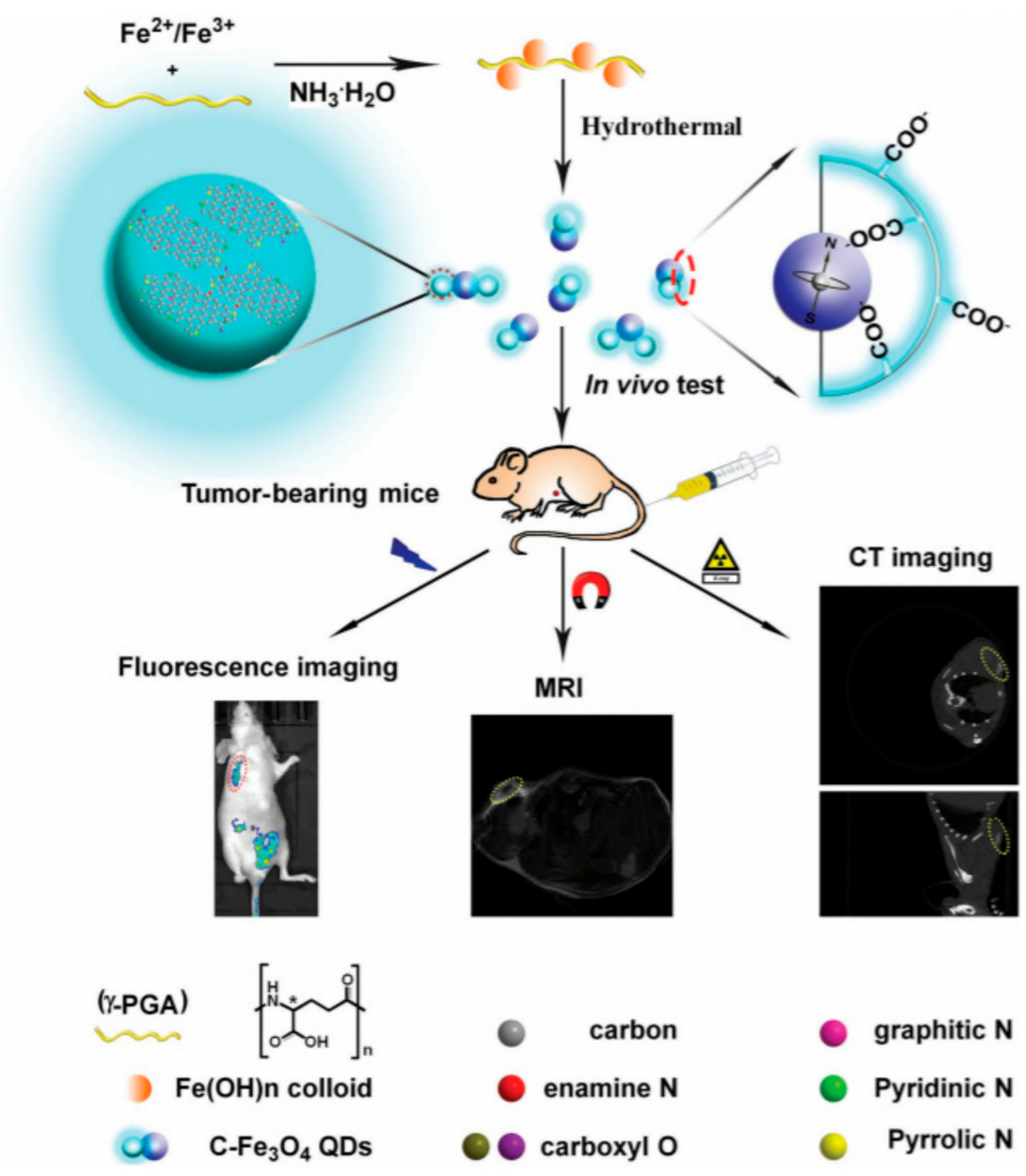

Figure 5. Schematics for the synthesis of $\mathrm{C}-\mathrm{Fe}_{3} \mathrm{O}_{4}$ quantum dots (QDs) showing the multimodal imaging application in vivo using HeLa tumor-bearing nude mice. Dotted circles indicate tumor sites. Reprinted with permission from ref. [48]. Copyright 2016 John Wiley and Sons.

Other than the bioluminescent property of CQDs, another interesting property, "ROS scavenging from the cellular microenvironment" can be utilized to reduce the cytotoxicity of bare IONPs. Owing to these properties, CQDs doped IONPs were explored for multimodal imaging, ROS scavenging, and as a 3D printed polymeric nanocomposite for osteochondral tissue engineering [49]. The fluorescence property of the nanocomposites was evaluated in vitro and showed bright fluorescence restricted to the cytoplasm. The $T_{2}$ MRI provided significantly higher contrast (relaxation rate: $118.3 \mathrm{mM}^{-1} \mathrm{~s}^{-1}$ ), proving its usefulness for $\mathrm{T}_{2}$ contrast imaging and MRI-based cells/scaffold tracking. The $\mathrm{T}_{2}$ weighted MRI in vivo 
projected a high-intensity dark contrast on the kidney and bladder after 30 min of injection. Furthermore, to check the in vivo response and differentiation capability of the samples, the nanocomposites were cultured with MSCs for seven days in the presence and absence of an external magnetic field. The fluorescent and magnetoactive 3D printed composites were implanted subcutaneously in a rodent model. Formation of the osteoblast-like nested island was observed in the magnetically actuated samples providing evidence for the mechanical stimuli-responsive differentiation of cells. Furthermore, the downregulation of the SOD gene via PCR in vitro also suggested the role of CQD doped IONPs as ROS scavenging agents.

To enhance the PTT effect along with dual-modal MRI, Shi et al. in 2013 reported the use of a new class of nanoparticles (plasmonic, see detail in class 5) into IONPs-graphene oxide (GO) nanocomposites [50]. Polyethyleneimine (PEI, $1.2 \mathrm{kDa}$ ) was physically adsorbed onto GO-IONPs, followed by attaching seeds of gold nanoparticles using $1 \%$ hydrogen tetrachloroaurate (III) hydrate $\left(\mathrm{HAuCl}_{4}\right)$. The resultant nanocomposites were further modified with folic acid (FA) conjugated lipoic acid (LA)-PEG. Under laser irradiation (808 nm, $\left.1 \mathrm{~W} / \mathrm{cm}^{2}, 5 \mathrm{~min}\right)$, the heating efficiency of GO-IONP-Au $(10 \mu \mathrm{g} / \mathrm{mL})$ nanocomposites was double compared to GO-IONP alone. Tumors treated under laser irradiation (power density: $0.75 \mathrm{~W} / \mathrm{cm}^{2}$ ) with GO-IONP-Au showed better ablation with negligible tumor cell growth.

Ma et al. in 2012 reported GO-IONP functionalized with PEG for in vivo MR imaging on 4T1 murine breast cancer model by magnetically targeted delivery of Doxorubicin and PTT guided by a magnetic field in $4 \mathrm{~T} 1$ cell lines [51]. The $\mathrm{T}_{2}$-weighted MRI images of GO-IONP-PEG ( $200 \mu \mathrm{L}$ of $2 \mathrm{mg} / \mathrm{mL}$ ) injected intravenously in BALB/c mice bearing tumor showed a significant decrease $(\sim 67 \%)$ of signal intensity.

\subsection{Class 4: Up-Conversion Nanoparticles-Iron Oxide Nanocomposites}

Up-conversion nanoparticles (UCNPs) are a class of nanomaterials that show the unique, non-linear optical phenomenon of photon up-conversion, whereby excitation with long-wavelength (low energy) light leads to the emission of shorter wavelengths (higher energy) light. This is made possible when certain trivalent rare-earth cations (e.g., $\mathrm{Ho}^{3+}$, $\mathrm{Er}^{3+}, \mathrm{Tm}^{3+}$, and $\mathrm{Yb}^{3+}$ ) with ladder-like energy levels are doped in low concentrations within inorganic matrices with low phonon energy materials (e.g., $\left.\mathrm{NaYB}_{4}\right)$. One practical application of photon up-conversion is the feasibility of NIR excitation to generate emission in either the visible or NIR region, thus significantly improving the depth-profiling in optical imaging [52]. A growing interest in the use of up-conversion nanoparticles (UCNPs) in bioimaging is due to their up-conversion property, providing higher signal-to-noise ratios, deeper tissue penetration, low auto-florescence, and lower photodamage than conventional luminescent probes [53]. The application of UCNPs in bioimaging and their clinical trials are still restricted because of their low up-conversion luminescence (UCL) efficiency in vivo. To improve efficiency, UCNPs can be combined with IONPs, which is the main focus of this section of the review.

Recently, $\mathrm{Fe}_{3} \mathrm{O}_{4} @ \mathrm{Mn}^{2+}$-doped $\mathrm{NaYF}_{4}: \mathrm{Yb} / \mathrm{Tm}$ nanoparticles (NPs) were synthesized as promising imaging agents for NIR-to-NIR UCL and $\mathrm{T}_{1} / \mathrm{T}_{2}$-weighted MRI [53]. IONPs $\left(\mathrm{Fe}_{3} \mathrm{O}_{4}\right)$ were used as seeds and covered with a NIR active shell of $\mathrm{Mn}^{2+}$-doped $\mathrm{NaYF}_{4}$ : $\mathrm{Yb} / \mathrm{Er}$ NPs using a facile hydrothermal method. To evaluate the NIR-to-NIR UCL imaging, a five-week-old nude mouse (male) was anesthetized and injected $10 \mathrm{~mm}$ beneath the abdomen region. The region of interest (ROI) analysis of the UCL signal $\left(\lambda_{\mathrm{em}}=800 \pm 12 \mathrm{~nm}\right)$ revealed a high signal-to-noise ratio $(\sim 26)$ between the abdomen region and the background. The ultra-low auto-fluorescence interferences with such a high signal could be attributed to the UCL of UCNPs featuring large anti-stokes shifts, in addition to the wavelength of the emission light that falls within the NIR window $(700-1000 \mathrm{~nm})$ for bioimaging. Furthermore, the $\mathrm{T}_{1}$-weighted MRI performed in vitro showed $\mathrm{T}_{1}$ relaxivity coefficient or relaxation rate $\left(\mathrm{r}_{1}\right)$ as $4.7 \mathrm{mM}^{-1} \mathrm{~s}^{-1}$, which is close to the relaxivity of commercial Gadolinium (Gd)-diethylenetriaminepentaacetic acid $\left(4.82 \mathrm{mM}^{-1} \mathrm{~s}^{-1}\right)$. 
Zhang et al. in 2012 synthesized 'nanorattles' consisting of $\mathrm{SiO}_{2}$-coated $\mathrm{Fe}_{3} \mathrm{O}_{4}$ and $\alpha-\mathrm{NaYF}_{4}: \mathrm{Yb} /$ Er shells, fabricated through an ion-exchange process for targeted chemotherapy in vivo [54]. The nanoparticles could emit visible light as luminescence upon NIR irradiation, manipulated using an external magnetic field, and loaded with Doxorubicin. Upon NIR irradiation (wavelength: $978 \mathrm{~nm}$ ), the visible spectrum with bands in two distinct regions was observed; one at around 510-570 $\mathrm{nm}$ (green region) and another at around 630-680 nm (red region). When intravenously injected in vivo and targeted magnetically, a significant increase in luminescence intensity was observed, demonstrating the accumulation of nanocarriers in tumors. The magnetic targeting of the Doxorubicin-loaded nanorattles (1 mg drug $/ \mathrm{kg}$ of nanocomposite) resulted in a $96 \%$ reduction in tumor size in $\mathrm{H} 22$ tumor-bearing mice.

Another combination of UCNPs and IONPs was achieved by layer-by-layer (LBL) assembly of hexagonal $\mathrm{NaYF}_{4}(\mathrm{Yb}: \mathrm{Er})$ UCNPs modified with polyacrylic acid (PAA) and iron oxides [55]. The dopamine-modified IONPs can be easily dispersed in water with excellent stability making them useful for the synthesis of UCNPs-IONPs nanocomposites. In their study, the UCNP-IONP was further modified with a layer of Au shell followed by Lipoic acid (LA) conjugated PEG. After intravenous injection of the modified UCNPsIONPs $(160 \mu \mathrm{L}$ of suspension with suspension density of $2.5 \mathrm{mg} / \mathrm{mL})$ in female nude mice bearing KB human epidermoid carcinoma tumors, the emission at $660 \mathrm{~nm}$ showed strong signals at liver and tumor sites suggesting higher uptake of nanocomposites. Later, Cheng and co-workers utilized the nanocomposite for an in vivo dual-modal optical/magnetic resonance imaging of $4 \mathrm{~T} 1$ breast cancer tumor developed in Balb/c mice [56]. They showed that by placing a magnet nearby the tumor, the intravenously injected nanocomposites tended to migrate toward the tumor showing better contrast enhancement. The nanoparticle accumulation was around eight-fold higher than that without magnetic targeting. Furthermore, NIR laser irradiation $\left(1 \mathrm{~W} / \mathrm{cm}^{2}\right)$ on tumors with an accumulation of nanocomposites under magnetic tumor-targeting showed an outstanding PTT efficacy with 100\% tumor elimination.

A multi-modal in vivo imaging technique (UCL imaging/FL imaging/MRI) combined with drug delivery has been reported using $\mathrm{Yb}$ /Er-doped UCNPs ( $\mathrm{Y}: \mathrm{Yb}: \mathrm{Er}=78 \%: 20 \%$ : $2 \%$ ) in combination with ultra-small IONPs encapsulated within an amphiphilic block copolymer PS16-b-PAA10 via a microemulsion method [57]. The study introduced a florescent dye (Squarine, SQ) into UCNPs-IONPs, and injecting in vivo intravenously; the UCL/FL imaging results are shown in Figure 6a. $\mathrm{T}_{2}$-weighted MRI of mice showed dark contrast in the liver (Figure 6b). The in vivo bio-distribution study of post-injected sacrificed mice showed a high accumulation of nanocomposites in the liver, spleen, and lungs, comparable with the FL and UCL imaging (Figure 6c). Averaged UCL and FL signals showed relatively high signal intensities in the liver compared to other organs (Figure 6d).

\subsection{Class 5: Plasmonic Nanoparticles-Iron Oxide Nanocomposites}

The optical features of plasmonic nanoparticles (PNPs) emanate from the property of localized surface plasmon resonance (LSPR), a resonant oscillation of surface electrons (plasmons) under visible light excitation. Nanoparticles of noble metals, such as gold and silver are well known for showing LSPR effects. Gold-based nanoparticles have been extensively used for optical bioimaging applications. Gold nanoparticles have a plasmonic signal in the visible region, whereas other nanostructures such as gold nanorods and nanoshells have tunable optical signal in the far red-NIR region [58]. Adding materials such as gold nanoshell protect the magnetic core from aggregation, oxidation, and corrosion. Likewise, gold nanoshells can also improve conductivity, optical properties, biocompatibility, surface functionalization, and chemical stability of IONPs [59,60]. In this context, interesting research was initiated nearly two decades ago to investigate the changes in magnetic properties of IONPs core by changing the thickness of gold shell [61]. Later in 2004, Lyon et al. reported the preparation of IONPs using co-precipitation of iron salts and the reduction of $\mathrm{Au}^{3+}$ to form a thin gold layer on its surface [62]. In 2007, 
Larson et al. reported that the magnetic-plasmonic formulation helped to tune plasmon bands to the NIR whilst maintaining the strong MRI contrast [63]. The combination of PNPs with IONPs has been utilized for the combined effect of MRI/optical imaging and PTT in MDA-MB-468 breast cancer cells with specificity. Even though the nanocomposites combined with PNPs and IONPs have been utilized for various in vitro applications, but there are very few in vivo studies. In this section, we have chronologically ordered and systematically evaluated combined PNPs-IONPs nanocomposites, specifically for in vivo biomedical applications.

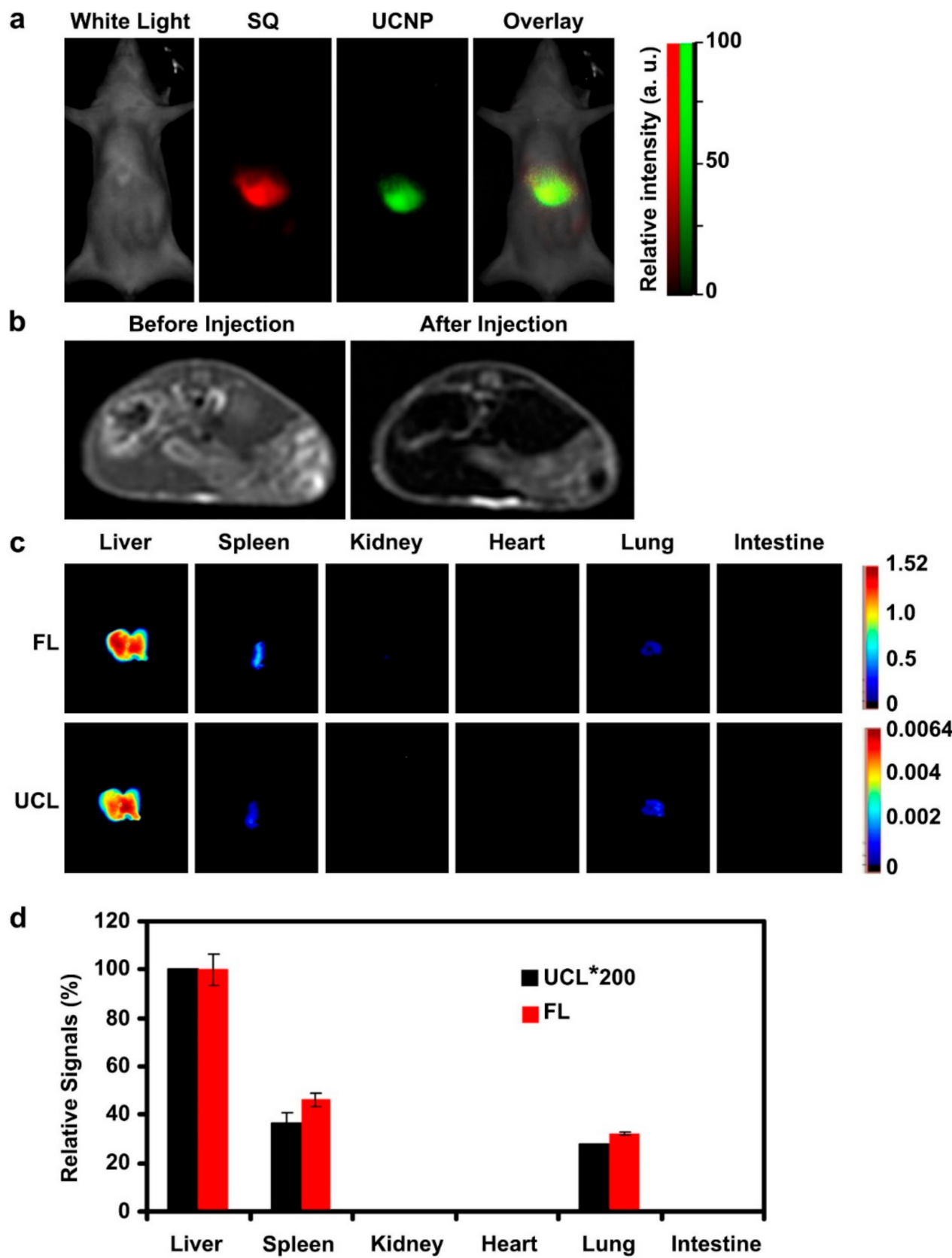

Figure 6. In vivo up-conversion luminescence (UCL)/fluorescent (FL)/MRI images of mice after intravenously injected up-conversion nanoparticles (UCNP)-iron oxide nanoparticles (IONP)-Polymer nanocomposite with Squarine (SQ) dye: (a) UCL (green) and FL (red) images (b) $\mathrm{T}_{2}$-weighted MRI images of mice before and after injection showing darkening effect in the liver. (c) Ex-vivo UCL/FL images of major organs post-injection. (d) Averaged UCL and FL signals of whole organs relative to the liver. Reprinted with permission from ref. [57]. Copyright 2011 Elsevier. 
Kim et al. in 2011, synthesized hybrid nanoparticles by combining IONPs with gold nanoparticles for in vivo applications using MRI and CT [64]. In their study, oleylamine stabilized $\mathrm{Au}-\mathrm{Fe}_{3} \mathrm{O}_{4}$ nanoparticles were synthesized by mixing Au-oleylamine and $\mathrm{Fe}-$ oleate complex solutions. Then, the hybrid nanoparticles were coated with amphiphilic poly (DMA-r-mPEGMA-r -MA). The optical absorption spectrum of the polymer-coated hybrid $\mathrm{Au}-\mathrm{Fe}_{3} \mathrm{O}_{4}$ displayed a red shift in the surface plasmon absorption band at $550 \mathrm{~nm}$, which was presumably attributed to the junction effect of these two nanoparticles and the polymer coating layers. The micro-CT and 3T MRI images obtained in hepatoma-bearing mice showed a good contrast enhancement ( 1.6-fold) after $1 \mathrm{~h}$ of injection of the nanoparticles. Furthermore, the $T_{2}$ relaxivity coefficient $\left(r_{2}\right)$ obtained as $245 \mathrm{mM}^{-1} \mathrm{~s}^{-1}$ was much larger than the commercial contrast agent, Resovist ${ }^{\circledR}$, with an $\mathrm{r}_{2}$ of $150 \mathrm{mM}^{-1} \mathrm{~s}^{-1}$. In 2012, Cai et al. reported a facile approach for the synthesis of iron oxide and gold nanocomposites $\left(\mathrm{Fe}_{3} \mathrm{O}_{4} @ \mathrm{Au} \mathrm{NCPs}\right)$ for MRI/CT dual in vivo imaging [65]. $\mathrm{Fe}_{3} \mathrm{O}_{4}$ was synthesized by a coprecipitation method and used as a core for subsequent electrostatic layer-by-layer assembly of PGA (poly(g-glutamic acid)) and PLL (poly(L-lysine)) to form PGA/PLL/PGA multilayers, followed by final assembly with dendrimer-entrapped gold NPs (Au DENPs). $\mathrm{The} \mathrm{Fe}_{3} \mathrm{O}_{4} @ \mathrm{Au} \mathrm{NCPs}$ presented relatively high $\mathrm{r}_{2}$ relaxivity $\left(71.55 \mathrm{mM}^{-1} \mathrm{~s}^{-1}\right)$ compared to uncoated $\mathrm{Fe}_{3} \mathrm{O}_{4}$ exhibiting multifunctionalities for dual imaging modalities (MRI and CT imaging) of the liver and subcutaneous tissues in C57 mice.

To accomplish the aim of combining PTT and chemotherapy in a remote-control manner, $\mathrm{Li}$ et al. in 2014 reported $\mathrm{Fe}_{3} \mathrm{O}_{4} @ \mathrm{Au} @ \mathrm{mSiO}_{2}$ nanocomposites using synthesized trisoctahedral core-shell $\mathrm{Fe}_{3} \mathrm{O}_{4} @ \mathrm{Au}$ nanoparticles covered with a mesoporous silica shell and tested their efficiency in vivo on mice bearing Hela tumors [66]. The reactive oligonucleotides (referred to as double-stranded DNA (dsDNA)) were used as pore blockers for mesoporous silica shells that allowed the controlled release of Doxorubicin and labeled as a NIR responsive DNA-gated $\mathrm{Fe}_{3} \mathrm{O}_{4} @ \mathrm{Au} @ \mathrm{mSiO}_{2}$ drug nanocarrier. By taking advantage of the magnetism due to IONPs, authors have managed to remotely trigger the drug release on the target site and monitored it with MRI imaging. Authors have reported a significant therapeutic effect on focusing the magnetic targeting of nanocarrier at the tumor site of mice bearing Hela tumors along with simultaneous irradiation of NIR laser light (wavelength: $808 \mathrm{~nm}$, power density: $3 \mathrm{~W} / \mathrm{cm}^{2}$ ), resulting in suppression of tumor growth due to the combination therapy.

Espinosa et al. in 2015 reported multicore IONPs (mostly $\mathrm{Fe}_{2} \mathrm{O}_{3}$ ) coated with Au shell and their application in vivo using dual therapies: MHT and PTT [67]. Maghemite $\left(\mathrm{Fe}_{2} \mathrm{O}_{3}\right)$ multi-core IONPs were synthesized via polyol process and further functionalized with citrate anions for efficient seeding of Au followed by decorating with spiked or multibranched gold shells. The magneto-plasmonic nanohybrids produced excellent heating efficiency with the temperature elevation of $6^{\circ} \mathrm{C}$ by the application of AMF (frequency; $900 \mathrm{kHz}$ and field: $25 \mathrm{mT}$ ) and NIR laser light (wavelength: $680 \mathrm{~nm}$; power density: $0.3 \mathrm{~W} \mathrm{~cm}^{-2}$ ) simultaneously. This is equivalent to heating power and was calculated to have a SAR value of $634 \pm 76 \mathrm{~W} \mathrm{~g}^{-1}$ of iron. The reason for such efficiency was explained earlier by Lartigue et al. in 2012, and it was due to the multi-core assembly potentiating thermal losses [68]. In the actual in vivo experiment, the nanocomposites were injected intratumorally on the subcutaneous tumor, and a temperature increase of almost $20^{\circ} \mathrm{C}$ was observed within 2 min by the application of AMF and NIR laser light simultaneously. Moreover, the heating efficiency remained the same even after three days of injection, and consequently, tumor regression was observed to be measurable following five days of regular combination therapy.

Li et al. in 2015 reported the use of hyaluronic acid-modified $\mathrm{Fe}_{3} \mathrm{O}_{4} @ \mathrm{Au}$ core/shell nanostars $\left(\mathrm{Fe}_{3} \mathrm{O}_{4} @ \mathrm{Au}-\mathrm{HA} \mathrm{NSs}\right)$ for theranostic application using MRI, CT, Thermal imaging, and PTT [69]. Core/shell nanostars were fabricated by using $\mathrm{Fe}_{3} \mathrm{O}_{4} @ \mathrm{Ag}$ nanoparticles as seeds for $\mathrm{Au}$ growth. The resultant core/shell nanostars $\left(\mathrm{Fe}_{3} \mathrm{O}_{4} @ \mathrm{Au}-\mathrm{HA}\right.$ NSs) were further modified by sequential addition of polyethyleneimine (PEI) and hyaluronic acid (HA) for colloidal stability, biocompatibility, and for specific targeting towards CD44 
receptor-overexpressing cancer cells, as shown in Figure 7i. HeLa tumor-bearing nude mice were used during the in vivo experiment, and nanocomposites were intratumorally injected and tested their efficiency by MRI and CT imaging. The tumor region darkened in a typical $\mathrm{T}_{2}$-weighted MRI study at $10 \mathrm{~min}$ post-injection with a significant difference in the signal intensity from 641 to 41 , as shown in Figure 7ii (panel a). Additionally, the CT image enhancement was also observed upon post-injection, as shown in Figure 7ii (panel b). Upon NIR laser irradiation (wavelength: $915 \mathrm{~nm}$; power density: $1.2 \mathrm{~W} / \mathrm{cm}^{2}$ ) for the period of 90 secs, a rapid temperature increase was observed from 32.8 to $58.9^{\circ} \mathrm{C}$ through the photothermal imaging.

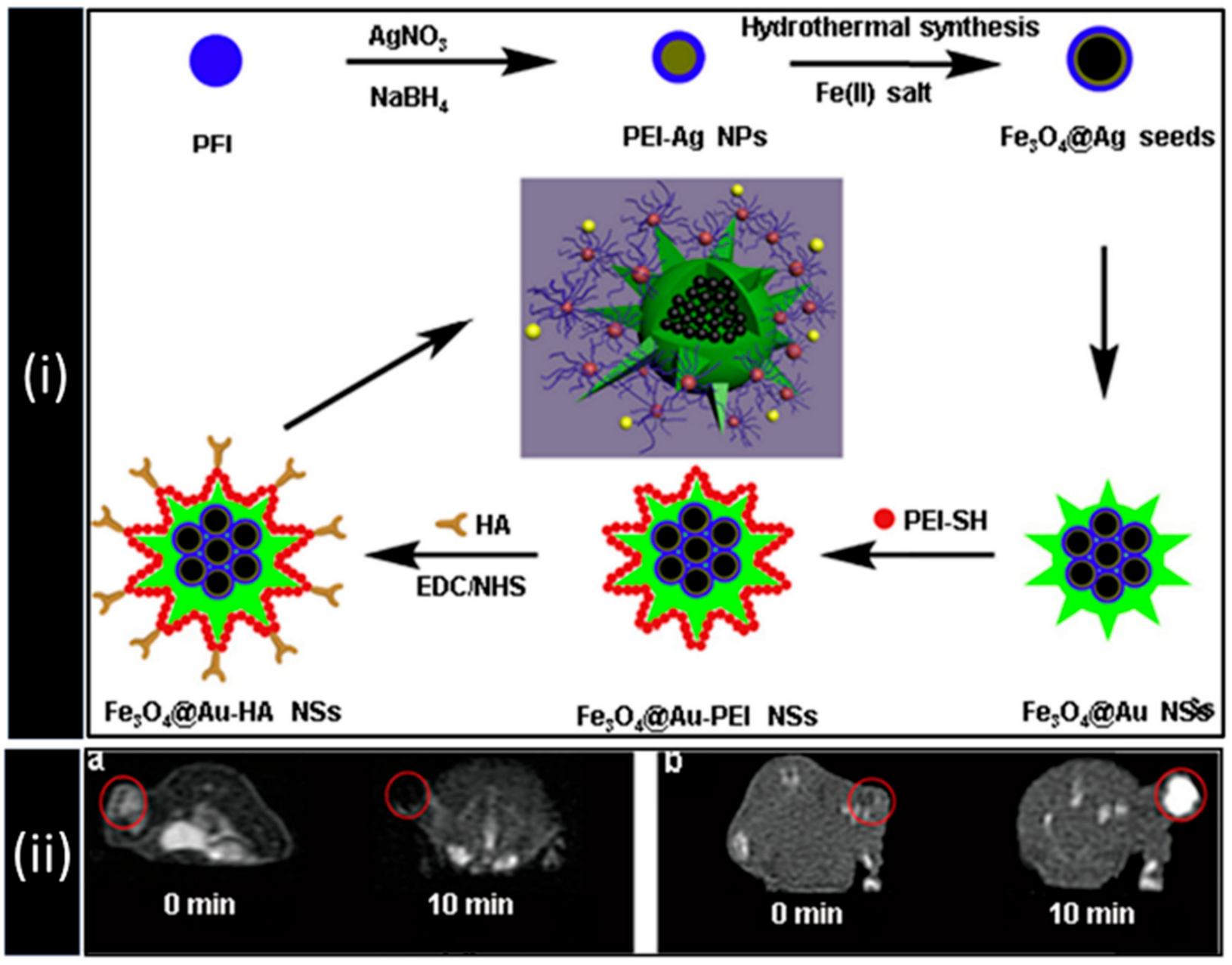

Figure 7. (i): Schematic illustration of the synthesis of $\mathrm{Fe}_{3} \mathrm{O}_{4} @ \mathrm{Au}-$ hyaluronic acid (HA) nanostars (NSs). (ii): (a) $\mathrm{T}_{2}{ }^{-}$ weighted MRI scan and (b) CT images of the tumors in a xenografted tumor model before injection and 10 min post intratumoral injection of nanocomposites. Red circles in Figure 7ii represent selected tumor sites. Reprinted with permission from ref. [69]. Copyright 2015 Elsevier.

In another study to reduce the number of nanoparticles being sequestered in the reticuloendothelial system (RES), Zhao et al. utilized the adipose-derived mesenchymal cells (AD-MSCs) with IO@AuNPs as a promising nanomaterial using a theranostic approach for injured livers and HCC [70]. IONPs of about $10 \mathrm{~nm}$ in diameter were coated with silica using the sol-gel method and seeded with gold. MRI and histological studies confirmed the IO@AuNPs loaded AD-MSCs preferentially accumulate on the diseased area. Later, the same group synthesized IO@AuNPs to label MSCs to test the feasibility of tracking carotid artery-injected superparamagnetic iron oxide nanoparticle (SPION)-Au via MRI and PA imaging for assessing the MSCs in glioma-bearing mice [71]. The localization of contrast agent labeled MSCs in neoplastic and ischemic lesions is a promising tool for the treatment 
of brain tumors such as Glioblastoma Multiforme (GBM). The addition of Au nanoparticles within the contrast labeled MSCs creates additional functionality for photoacoustic imaging (PAI), helping to map brain tumors. IO@AuNPs were stabilized by using PVP and amino-functionalized methyl-PEG. Green fluorescent protein (GFP) conjugated MSCs were labeled with IO@AuNPs at $4 \mu \mathrm{g} / \mathrm{mL}$ and injected via the internal carotid artery in six male athymic nude mice (NU/NU) bearing orthotopic U87 tumors. The in vivo $\mathrm{T}_{2}$-weighted MRI after injection of labeled MSCs showed progressive hypointensity of tumors over time. Similarly, an enhancement of the PAI signal was observed after the injection of labeled MSCs by comparing with unlabeled MSCs. The co-localization of GFP and iron from IONPs was confirmed via histological analysis even after $72 \mathrm{~h}$ of injection, indicating IO@AuNP labeled MSCs continue to carry their nanoparticle payloads, whereas the control MSCs did not show co-localization. Thus, the results suggest that a combination of PAI and MRI using IO@AuNPs is powerful for planning and real-time monitoring during stem cell-mediated therapy on brain tumors.

With an effort to study PTT and MRI on cancer cells initially in vitro, Shakeri-Zadeh and co-workers synthesized cysteamine-folic acid conjugated $\mathrm{Fe}_{2} \mathrm{O}_{3} @ A u$ nanoparticles [72]. The folic acid (FA) conjugated nanoparticles (hydrodynamic diameter within 30-70 nm; among less than a $3 \mathrm{~nm}$ gold layer) displayed a red shift in the surface plasmon band (absorption peak: $563 \mathrm{~nm}$ ), making them well-suited NIR photothermal agents. Later, the same materials were utilized for PTT and MRI in vivo [73]. The bio-distribution of nanoparticles on CT26 colon tumor-bearing mice was monitored by MRI study, and therapeutic effect was monitored by irradiating NIR laser light (wavelength: $808 \mathrm{~nm}$; power density: $1.4 \mathrm{~W} / \mathrm{cm}^{2}$ ). The $\mathrm{T}_{2}$-weighted MRI of the tumor under an external magnetic field resulted in darker regions compared to the non-targeted area, confirming the accumulation of nanocomposites due to the application of an external magnetic field. Upon NIR laser irradiation on a magnetically targeted region of interest after intravenous and intratumoral injection, temperature rises of $12{ }^{\circ} \mathrm{C}$ and $16.7^{\circ} \mathrm{C}$ were observed, respectively, showing an efficient PTT effect. Interestingly, the antitumor effect of nanocomposites by magnetically targeted localization followed by PTT with an intravenous injection was reported to be similar in efficiency to the intratumoral injection. However, as an intratumoral injection is not feasible for most tumor sites, therefore, intravenous injection is a preferable option-nanocomposite accumulation upon magnetic targeting and subsequent PTT by irradiating NIR laser light dramatically suppressed tumor growth.

Other than gold, silver is another plasmonic nanoparticle used in combination with IONPs for in vivo biomedical application. $\mathrm{Ag} @ \mathrm{Fe}_{3} \mathrm{O}_{4}$ with evenly enclosed carbon shells as multifunctional nanocomposites were used for theranostic application in vivo [74]. The nanocomposites were loaded with Doxorubicin and coated with PEG, followed by modification with folate. The resultant nanocomposites were reported to be around $140 \mathrm{~nm}$ in diameter, superparamagnetic in nature (saturation magnetization value $=102 \mathrm{emu} \mathrm{g}^{-1}$ ), drug loading efficiency of $17.5 \%$, and a transverse relaxivity $\left(\mathrm{r}_{2}\right)$ of $82.1 \mathrm{mM}^{-1} \mathrm{~s}^{-1}$ in vitro. In an in vivo MRI study on tumor-bearing mice, a high-intensity MRI signal at the tumor site was observed, which could be due to the deposition of nanoparticles through the EPR effect. Similarly, HeLa tumor-bearing mice were used for in vivo optical imaging study using NIR laser irradiation (wavelength: $808 \mathrm{~nm}$; power density: $1.5 \mathrm{~W} / \mathrm{cm}^{2}$ ). A temperature rises to $55{ }^{\circ} \mathrm{C}$ was reported after $5 \mathrm{~min}$ of NIR light irradiation. The fluorescence imaging after $24 \mathrm{~h}$ of injection showed the highest intensity due to the presence of nanocomposites in the tumor region, complementary with MRI. Furthermore, the tumor volume decreased significantly in the mice, indicating the high efficiency due to the nanocomposites' formulation compared to Doxorubicin alone.

Curcio et al. designed core-shell nanohybrid with iron oxide and $\mathrm{CuS}$ for tri-modal cancer therapy with simultaneous MHT (SAR $\sim 350 \mathrm{~W} / \mathrm{g}$ ), PDT and PTT (T $\sim 46{ }^{\circ} \mathrm{C}$, $\eta \sim 42 \%$ ) under AMF (frequency: $471 \mathrm{kHz}$, field: $18 \mathrm{mT}$ ) and laser light of wavelength $1064 \mathrm{~nm}$ [75]. CuS was chosen over other photothermal agents (i.e., gold or silver) owing to its NIR-II absorption with high PDT efficiency [76]. The authors used maghemite $\left(\alpha-\mathrm{Fe}_{2} \mathrm{O}_{3}\right)$ 
coated with NIR-II-absorbing plasmonic CuS shell (LSPR band centered at $1050 \mathrm{~nm}$ ) as nanohybrid materials with a size of around $120 \mathrm{~nm}$. Multicore iron oxide (IO) nanoflowers (SAR $\sim 500 \mathrm{~W} / \mathrm{g}$ ) as magnetic cores are reported to be more efficient for localized heating over single domain nanocrystals. Authors have explained that nanoflowers do not form dipole-dipole chains, which inhibit their aggregation [77]. Nanohybrid induced ROS even in the absence of laser and stimulate ROS production in the presence of laser, indicating their potential use as PDT agents. In an in vivo study using tumor-bearing mice, nanohybrids showed an excellent PAI (wavelength $=905 \mathrm{~nm}$ ). Furthermore, even at a low concentration of nanohybrids $(0.6 \mathrm{mM} \mathrm{Cu}, 0.1 \mathrm{mM} \mathrm{Fe})$, the temperature of tumors reached $53{ }^{\circ} \mathrm{C}$ under laser light irradiation for only $10 \mathrm{~min}$ whereas the similar temperature rise observed under MHT required nearly a thousand folds higher dose $(650 \mathrm{mM} \mathrm{Cu}, 100 \mathrm{mM} \mathrm{Fe})$, highlighting the superiority of the PTT effect of the nanocomposites over MHT. Another study showed that an IONP core and CuS shell nanocomposite with Doxorubicin could be a platform for tumor chemotherapy, PTT, and PDT [78]. Doxorubicin release could be triggered by the presence of gelatinase, showing enzyme responsive release in MCF-7 cells along with a synergistic cytotoxic response by laser irradiation (wavelength: $980 \mathrm{~nm}$ ), leading to enhanced intracellular ROS generation compared to Doxorubicin alone. The temperature increased to $42{ }^{\circ} \mathrm{C}$ within $2 \mathrm{~min}$ of laser irradiation. Table 1 summarizes the combination of IONPs and class 5 nanocomposites for in vivo biomedical application. 
Table 1. Plasmonic nanoparticles—iron oxide nanocomposites for in vivo biomedical application.

\begin{tabular}{|c|c|c|c|c|c|c|c|}
\hline $\begin{array}{c}\text { Nanoparticles } \\
\text { Composition }\end{array}$ & Synthesis (Magnetic NPs) & Synthesis (Optical NPs) & $\begin{array}{c}\text { Synthesis } \\
\text { (Nanocomposites) }\end{array}$ & $\begin{array}{l}\text { Magnetization } \\
\text { (emu/g) }\end{array}$ & $\mathrm{T}_{2}$ Relaxivity $\left(\mathrm{mM}^{-1} \mathrm{~s}^{-1}\right)$ & In Vivo Tumor Model & In vivo Application \\
\hline $\begin{array}{l}\mathrm{Fe}_{3} \mathrm{O}_{4} \text {-Au-poly(DMA-r- } \\
\text { mPEGMA-r-MA) }\end{array}$ & Thermal decomposition & Thermal decomposition & Emulsion & $\mathrm{N} / \mathrm{A}$ & 245 & $\begin{array}{l}\text { MCA-TL cells bearing } \\
\text { orthotopic hepatoma } \\
\text { mice model }\end{array}$ & $\begin{array}{l}\mathrm{CT} \text { and MRI dual contrast } \\
\text { agents for hepatoma } \\
\text { imaging [64] }\end{array}$ \\
\hline $\begin{array}{l}\text { Magnetic cluster-Au } \\
\text { nanorods }\end{array}$ & $\begin{array}{l}\text { High-temperature } \\
\text { hydrolysis method }\end{array}$ & Seed mediated & $\begin{array}{l}\text { Microfluidic fabrication } \\
\text { (Droplet gelation process) }\end{array}$ & N/A & $\mathrm{r}_{2}\left(=1 / \mathrm{T}_{2}\right)=15.2 \mathrm{mg}^{-1} \mathrm{~s}^{-1}$ & HCC orthotopic rat model & $\begin{array}{l}\text { Improving the treatment of } \\
\text { hepatic malignancies } \\
\text { through transcatheter } \\
\text { intra-arterial drug delivery } \\
\text { system with MRI and CT } \\
\text { imaging [79] }\end{array}$ \\
\hline IONPs-Au-PEG & $\begin{array}{l}\text { Commercial (EMG 304) } \\
\text { coated with silica by a } \\
\text { gel-sol method }\end{array}$ & $\begin{array}{l}\text { Seed mediated growth } \\
\text { of gold shell on IONPs }\end{array}$ & $\begin{array}{l}\text { Nano-shell coated } \\
\text { with PEG }\end{array}$ & $\begin{array}{c}3.5 \\
\text { (at } 20 \mathrm{kOe} \text { ) }\end{array}$ & 369 & $\begin{array}{l}\text { Athymic nude mice } \\
\text { bearing orthotropic } \\
\text { U87 tumors }\end{array}$ & $\begin{array}{l}\text { To label MSCs to track } \\
\text { nanocomposite for MRI } \\
\text { and PA imaging [71] } \\
\text { MRI/CT contrasting for } \\
\text { tumor imaging and }\end{array}$ \\
\hline $\begin{array}{c}\mathrm{Fe}_{3} \mathrm{O}_{4}-\mathrm{Ag} @ \mathrm{Au}-\mathrm{HA} \\
\text { nanostars }\end{array}$ & Hydrothermal & Seed mediated & Modified with PEI and HA & $\mathrm{N} / \mathrm{A}$ & 144.39 & Hela tumor-bearing mice & $\begin{array}{l}\text { Photothermal imaging } \\
\text { mediated therapy under } \\
915 \mathrm{~nm} \text { laser irradiation } \\
\left(1.2 \mathrm{~W} / \mathrm{cm}^{2}\right)[69]\end{array}$ \\
\hline $\mathrm{Fe}_{2} \mathrm{O}_{3}-\mathrm{Au}-\mathrm{FA}$ & Co-precipitation & Seed mediated & $\begin{array}{l}\text { Conjugation of } \\
\text { cysteamine-FA }\end{array}$ & $\sim 40$ & N/A & CT26 bearing colon tumor & $\begin{array}{l}\text { PTT under NIR irradiation } \\
\left(808 \mathrm{~nm}, 1.4 \mathrm{~W} / \mathrm{cm}^{2}\right) \text { for } \\
\text { efficient eradication of } \\
\text { tumor cells with MRI } \\
\text { guidance under MAT [73] }\end{array}$ \\
\hline $\begin{array}{c}\mathrm{Fe}_{3} \mathrm{O}_{4} @ \mathrm{Ag} @ \\
\text { Carbon-PEG-FA/Dox }\end{array}$ & Solvothermal reaction & Solvothermal reaction & $\begin{array}{l}\text { Hydrothermal reaction } \\
\text { with addition of PEG, FA, } \\
\text { and Dox }\end{array}$ & 102 & 82.1 & Hela tumor-bearing mice & $\begin{array}{l}\text { MRI/FL for tumor } \\
\text { imaging and PTT under } \\
\text { NIR irradiation at } 808 \mathrm{~nm} \\
\left(1.5 \mathrm{~W} / \mathrm{cm}^{2}\right)[74]\end{array}$ \\
\hline $\mathrm{PPy} @ \mathrm{Fe}_{3} \mathrm{O}_{4} / \mathrm{Au}$ & $\begin{array}{c}\text { Emulsion polymerization } \\
\text { with PVA }\end{array}$ & Nucleation & Electrostatic adsorption & - & 360.8 & $\begin{array}{l}\text { HeLa cell-bearing } \\
\text { nude mice }\end{array}$ & $\begin{array}{c}\text { MR and CT } \\
\text { imaging-guided efficient } \\
\text { photothermal ablation of } \\
\text { tumors [80] }\end{array}$ \\
\hline
\end{tabular}

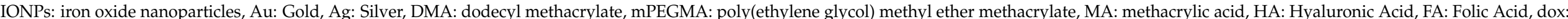

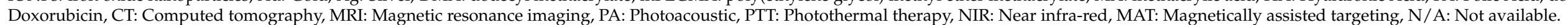




\subsection{Class 6: Other Optical-Iron Oxide Nanocomposites}

In this section, we present all other optical probes which do not belong to the above five classes and have been utilized for in vivo studies. Surface modification of inorganic nanoparticles is important for biomedical applications as it improves biocompatibility, colloidal stability, and hydrophilicity. In this context, covalent bonding of polymers on inorganic nanoparticles are usually performed through two major approaches (i) 'grafting to' and (ii) 'grafting from'. The 'grafting to' method allows functionalization through chemical reaction on the surface of nanoparticles with low-density polymers. Whereas the 'grafting from' method uses an initiator surface where layers of high-density polymers are grafted, leading to high graft density nanocomposites. In 2011, Li et al. used a specific polymerization technique called reversible addition-fragmentation chain transfer (RAFT), where a florescent carbazole agent was functionalized on magnetic silica nanoparticles as a chain transfer agent and $\mathrm{N}$-isopropylacrylamide (NIPAM) as the monomer [81]. The resultant nanocomposite displayed effective negative contrast MRI. The suggestion on synthesizing a fluorescent polymer for efficient MRI was adopted by Yan et al. in 2014 to synthesize polymeric micelles with a fluorescent polymeric shell and core IONPs with a hydrodynamic diameter of $146 \mathrm{~nm}$ [82]. A carbazole containing monomer, 9-(4-vinylbenzyl)-9H-carbazole, was polymerized with 2,2,3,4,4,4-Hexafluorobutyl methacrylate (HFMA) by free radical polymerization to produce an amphiphilic poly(HFMA-co-VBK)-g-PEG copolymers that acted as a shell for encapsulating $\mathrm{Fe}_{3} \mathrm{O}_{4}$ magnetic nanoparticles. The micelles exhibited paramagnetic properties (Ms: $9.61 \mathrm{emg} / \mathrm{g}$ ) and a transverse relaxivity rate of $157.44 \mathrm{mM}^{-1} \mathrm{~s}^{-1}$. The in vivo MRI study in an SD mouse model showed high contrast region on the liver and spleen, suggesting nanocomposites uptake by the reticuloendothelial system (RES). The ex vivo images obtained by 2-photon (690-1040 nm) laser confocal microscopy (CLSM) demonstrated unique blue fluorescence in the liver showing distinctive characteristics of the carbazole containing $\mathrm{Fe}_{3} \mathrm{O}_{4}$-encapsulated polymeric micelles. Thus, the nanocomposites showed their potential for clinical use as MRI and optical imaging agents.

Polymers such as PDA (Polydopamine), a dopamine-derived synthetic polymer, exhibited a promising PTT effect when combined with IONPs in cancer theranostics. Recently, $\mathrm{Li}$ et al. constructed a nanocomposite of $\mathrm{Fe}_{3} \mathrm{O}_{4}$ coated with a PDA shell, which provided excellent stability with improved PTT [83]. The nanocomposites showed temperature rise to $57^{\circ} \mathrm{C}$ upon laser light irradiation (wavelength: $808 \mathrm{~nm}$ laser, Power density: $1 \mathrm{~W} / \mathrm{cm}^{2}$ ). The transverse relaxivity $\left(\mathrm{r}_{2}\right)$ was reported to be $337.8 \mathrm{mM}^{-1} \mathrm{~s}^{-1}$, which was comparatively higher than the commercial MRI contrast agents such as Resovist $\left(143 \mathrm{mM}^{-1} \mathrm{~s}^{-1}\right)$. The nanocomposites were intravenously injected in the 4T1 bearing mice for evaluation of therapeutic effect and MRI study. Following laser irradiation, the tumor size decreased dramatically without any recurrence within 15 days of study. After $24 \mathrm{~h}$, the $\mathrm{T}_{2}$-weighted MRI signal increased significantly on the tumor site.

Some of the lanthanide-based complexes can also act as extremely useful optical probes due to their excellent luminescence properties, such as large stokes shifts, high quantum yield, narrow emission bandwidth, longer lifetimes, and higher photostability compared to other optical probes [84]. Wang et al. in 2015 reported a novel nanocomposite by integrating IONPs (e.g., $\mathrm{Fe}_{3} \mathrm{O}_{4}$ ), rare earth fluorescent element Europium and small iodine as a contrast agent for multimodal imaging [84]. The nanocomposites possessed good paramagnetic properties with a maximum saturation magnetization of $2.16 \mathrm{emu} \mathrm{g}^{-1}$, transverse relaxivity rate $\left(r_{2}\right)$ of $260 \mathrm{mM}^{-1} \mathrm{~S}^{-1}$. The $\mathrm{T}_{2}$-weighted MRI on Sprague-Dawley (SD) rats showed relatively higher darkening on the liver and spleen compared to the kidney and muscles, indicating uptake of nanocomposites by the macrophages of RES. When subjected to in vivo optical imaging by 2-photon confocal scanning laser microscopy (CLSM), vivid fluorescent red dots were observed from the liver and spleen, complying with the presence of $\mathrm{Eu}^{3+}$ ions in the nanocomposite, exhibiting characteristic red luminescence. The CT images, when studied in vitro, showed increased intensity with an increase in iodine payload on the nanocomposites, thus showing the possibility of being tri-functional con- 
trast agents having great clinical potential in CT, MRI, and optical imaging. Self-assembled magnetic luminescent hybrid micelles containing rare earth Eu have also been reported in in vivo experiments for dual-modality, i.e., MRI and optical imaging [85]. The resultant nanoparticles self-assembled to form magnetic and luminescent hybrid micelles and exhibited spherical morphology, paramagnetic properties (maximum saturation magnetization of 7.05 emu $\left.\mathrm{g}^{-1}\right)$, and a high transverse relaxivity of $340 \mathrm{mM}^{-1} \mathrm{~s}^{-1}$. When applied in in vivo MRI study, the nanocomposites showed excellent contrast of the liver and spleen. Fluorescence spectra showed characteristic emission peaks from the rare earth Eu at $616 \mathrm{~nm}$ and vivid red fluorescence by 2-photon confocal laser scanning microscopy (CLSM).

\section{Toxicity and Challenges for Potential Clinical Trials}

Concurrent with the development of novel biomedical applications of nanomaterials, serious questions have been raised about the possible pitfalls of their use, particularly for in vivo administration due to unknown cytotoxicity [86]. This had led to some extensive in vivo toxicological analyses of such nanoparticles, especially their chemical composition, sizes, shapes, chemical stability, surface properties, route of administration, tendency for biodegradation, and their biocompatibility. Considering chemical composition perspectives, it has been generally agreed that most inorganic nanoparticles, such as iron oxide, silica, carbon, and gold, are mostly non-toxic $[87,88]$. However, detailed investigations have revealed that owing to the degradation, and poor elimination of 'innocuous' nanoparticles, i.e., iron oxide, several potential biohazards, such as hemolysis, anaphylaxis, sepsis, off-target organ toxicity, etc., may occur [89-91].

The majority of the nanocomposites described in this review article brings an additional toxicological perspective due to their optical components with magnetic IONPs, therefore, requiring a new set of investigations. The obvious physical aspect of IONP modification will be the size and shape. Generally, IONPs alone are usually considered spherical, ultra-small in diameter, and monodisperse; however, their modification with optical probes, particularly nanoparticulate forms, can lead to shape deformation, increase in size, alteration of surface charge, and polydispersity in suspension. In connection with the alteration in surface charge and shell material of IONPs based core/shell nanoparticles, a significant change due to protein adsorption (formation of protein corona) is observed, thus, influencing how cells recognize them [92]. Such physical transformation comes with the risk of capture by the reticuloendothelial system (RES), altered pharmacokinetics/pharmacodynamics, non-specificity, long-term persistence in the body, modulating uptake pathways, etc. Moreover, their combination with heavy-metal containing optical probes, such as II-VI quantum dots, can lead to enhanced toxicity. Another key factor while considering IONPs linked to optical probes is the potential for light-induced toxicity if these nanocomposites end up in superficial off-target organs such as the skin and eye [93].

Uptake of IONPs in the cellular system and the mechanism of toxicity are well documented from a biological perspective [94] whereas the combination of optical probes with IONPs is pre-mature and requires further study. Based on the current literature, with well-known mechanisms of toxicity [95], we have summarized the possible biological pathways of IONPs-based nanocomposites induced cellular toxicity, and an extension to opto-magnetic nanoparticles has been proposed in this article. Figures 8 and 9 represent schematic diagrams of possible pathways for cellular toxicity.

Biomolecules that are charged or polar are unable to cross the hydrophobic plasma membrane; hence they can be internalized by active transport called endocytosis. Sizedependent cellular uptake of iron oxide-based nanocomposites occurs through different mechanisms such as passive diffusion, receptor-mediated endocytosis, clathrin-mediated endocytosis, caveolin mediated endocytosis, etc., result in a myriad of intracellular responses causing major cellular stress (see Figure 8). Large molecules (in the range of $250 \mathrm{~nm}$ ) are taken-up by large vesicles, and pinocytosis encompasses uptake through small vesicles in the range of a few to hundreds of nanometers [96]. Pinocytosis can be subclassified into caveolin-mediated endocytosis, clathrin-mediated endocytosis, caveolae- 
and clathrin-independent endocytosis, and macro-pinocytosis [97]. Furthermore, specific molecules may be internalized in the cells through specific receptors, such as cholesterol via low-density lipoprotein receptor and iron $\left(\mathrm{Fe}^{3+}\right)$ via transferrin receptor facilitated by Clathrin-mediated endocytosis. Once inside the cell, clathrin coatings on the exterior of the vesicles are ejected prior to fusion with early endosomes. The cargo (nanoparticulates or nanocomposites) within early endosomes may ultimately reach lysosomes via the endolysosomal pathway. In caveolin-mediated endocytosis, caveolae, internalizing molecules in the range of $50-80 \mathrm{~nm}$, are composed of the membrane protein caveolin- 1 that gives them a flask-shaped structure. Caveolae exist in epithelial cells, endothelial, skeletal muscles, adipocytes, and fibroblasts cells [98]. Cell signaling and regulation of membrane proteins, lipids, and fatty acids are controlled by Caveolae-dependent endocytosis. After caveolae are separated from the plasma membrane, they bind with a compartment of cell called caveosomes, which maintain a neutral $\mathrm{pH}$. Caveosomes circumvent lysosomes, thereby protecting the contents from lysosomal degradation by hydrolytic enzymes. Therefore, pathogens, including bacteria and viruses, enter through this route to avert degradation. This pathway is exploited in nanomedicine as the cargo that is internalized by a caveolindependent mechanism evading lysosomes [97]. Other mechanisms of endocytosis such as clathrin- and caveolin-independent endocytosis occurs in cells when the cell surface lacks clathrin and caveolin. The dissolution of lysosomes increases the iron ions $\left(\mathrm{Fe}^{2+}\right)$ release into lumen that further increases calcium levels leading to a partial loss of mitochondrial membrane potential (MMP) and eventually causing ATP depletion; hence Cytochrome c (Cyt c) release responsible for gene alteration. The elevated ER stress helps in the activation of effector caspases that trigger p53 dependent apoptosis. The accumulation of free iron ions $\left(\mathrm{Fe}^{3+}\right)$ in cell lumen initiates oxidative stress and the Fenton reaction, which are reported to be two main reasons for cellular toxicity [94]. The co-existence of iron ions $\left(\mathrm{Fe}^{+2}\right)$ from IONPs and $\mathrm{H}_{2} \mathrm{O}_{2}$ in the cellular system initiates the Fenton reaction $\left(\mathrm{Fe}^{2+}+\mathrm{H}_{2} \mathrm{O}_{2}\right.$ $\left.\rightarrow \mathrm{Fe}^{3+}+\mathrm{OH}+\mathrm{OH}^{-}\right)$and produces hydroxyl radicals $(\mathrm{OH})$, a powerful oxidant creating additional oxidative stress on the tumor cells.

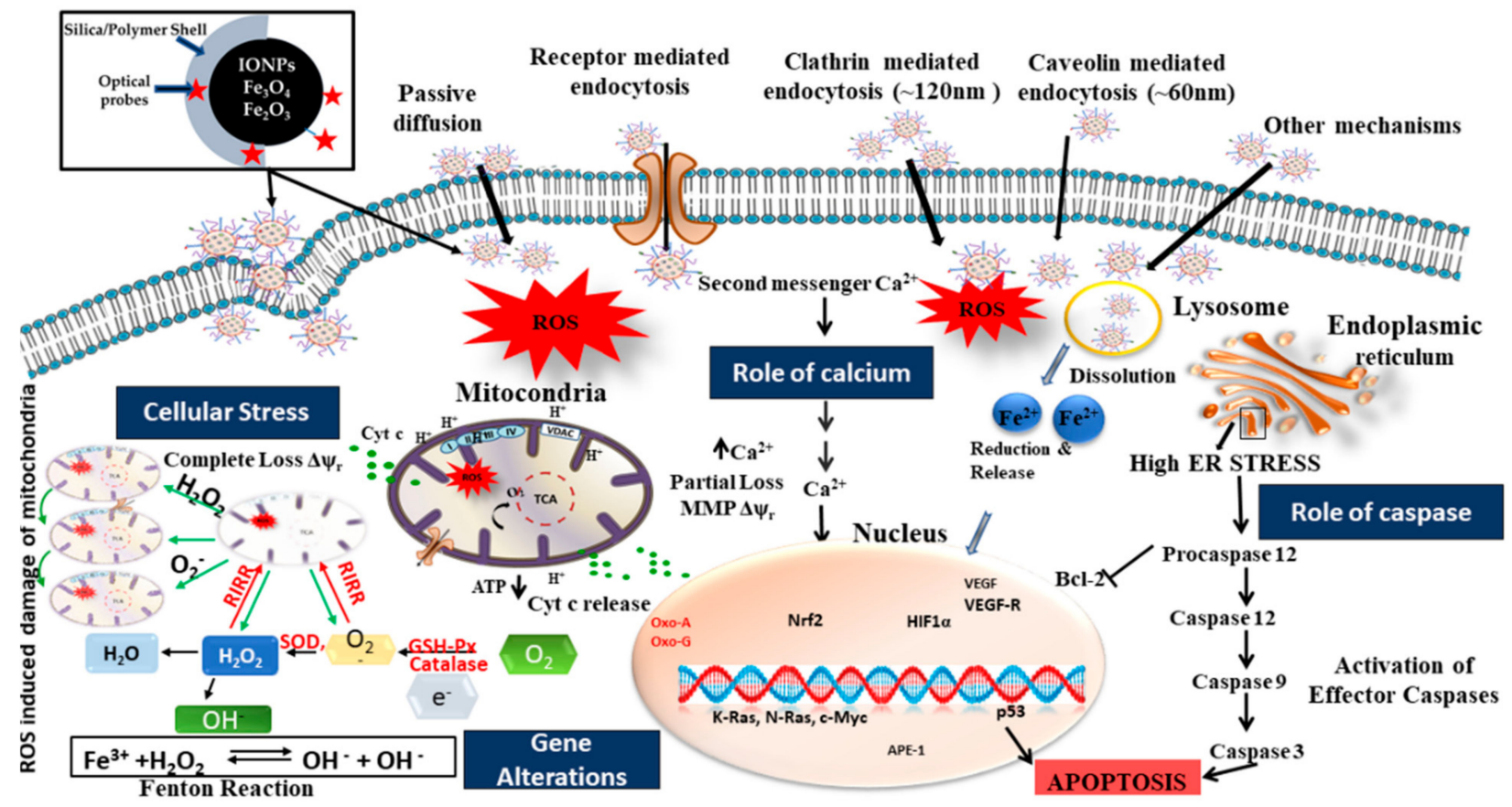

Figure 8. Possible mechanisms of iron oxide-based nanocomposites induced toxicity at the cellular level. 


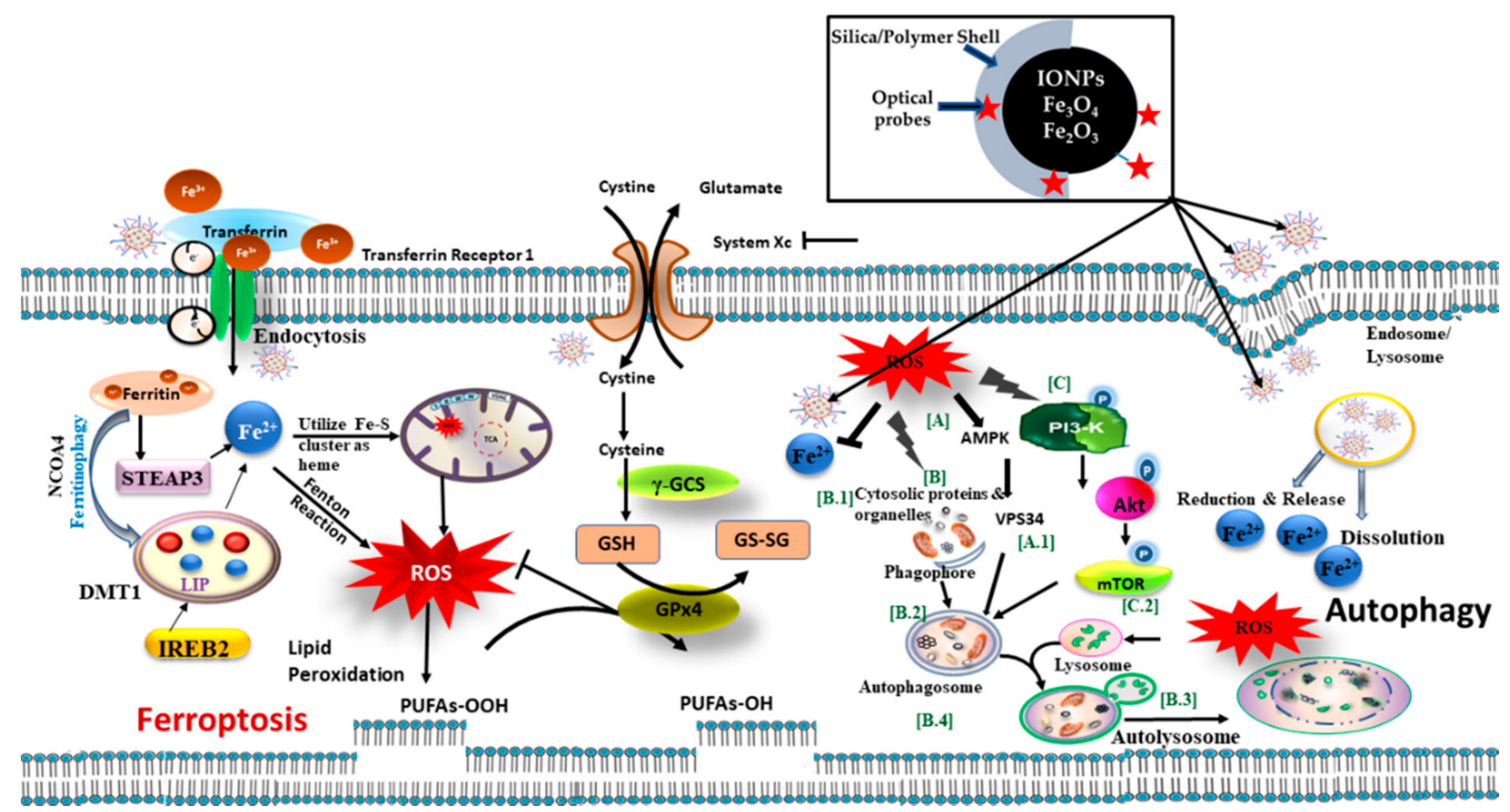

Figure 9. Molecular pathways induced by iron oxide-based nanocomposites.

Excess iron ions can play a vital role in initiating the ferroptosis pathway. The $\mathrm{Fe}^{3+}$ ions in circulation, along with the additional iron ions $\left(\mathrm{Fe}^{2+}\right)$ released from nanocomposites, may enter into the cells through the transferrin receptor (see Figure 9). The $\mathrm{Fe}^{3+}$ ions get reduced to $\mathrm{Fe}^{2+}$ under the catalytic effect of STEAP3 (six-transmembrane epithelial antigen of prostate 3), i.e., iron oxide reductase [99]. The $\mathrm{Fe}^{2+}$ ions accumulate into the labile iron pool (LIP) with the help of a divalent metal transporter 1 (DMT1). This may be due to the electron transfer ability and high solubility of $\mathrm{Fe}^{2+}$. LIP holds iron from the degradation of ferritin (ferritinophagy) and endosomal uptake of circulated iron ions. Increasing LIP formation may trigger the Fenton reaction and enhanced ROS level followed by ferroptotic cell death. Furthermore, System $\mathrm{Xc}^{-}$mediates the uptake of glutamate and cystine that are constituents of glutathione (GSH), an important detoxifying molecule in the cells. However, the inhibition of System $\mathrm{Xc}^{-}$impairs the intake of cystine following lipid peroxidation [100]. The lipoxygenases (LOXs) mediate the oxidation of PE-PUFAs to PE-PUFAs-OOH, eventually leading to ferroptosis. GPX4 plays a role as a protector to transfer PE-PUFAs-OOH to PE-OH and IREB2 as an iron-responsive binding protein 2. ROS-induced autophagy is another pathway that involves the destruction of $(\mathrm{A})$ cytosolic proteins and organelles, (B) AMPK, (C) PI-3K and the formation of phagosome and autolysosomes. IONPs enter cells via endocytosis and stimulate the formation of phagophores, which support cargo sequestration. After completion, phagophores grow as autophagosomes and fuse with lysosomes to eventually form autolysosomes that will discharge their contents into the lumen. Iron ions either induce inhibition of autophagy through alteration in Akt/mTOR pathway or lysosomal impairment to trigger autophagy.

Recently Huo et al. have reported possible pathways for cellular toxicity by optical nanoparticles induced PTT and PDT [101]. Irradiation of NIR laser light (wavelength: $1064 \mathrm{~nm}$ ) induces cell necrosis during PTT, whereas in combination therapies (PTT + PDT), both apoptosis and necrosis pathways are responsible for cellar toxicity. In addition, an anticancer effect can be induced by the endoplasmic reticulum and mitochondria due to the combination of PTT-PDT simultaneously, responsible for immunogenic cell death (see Figure 10). 


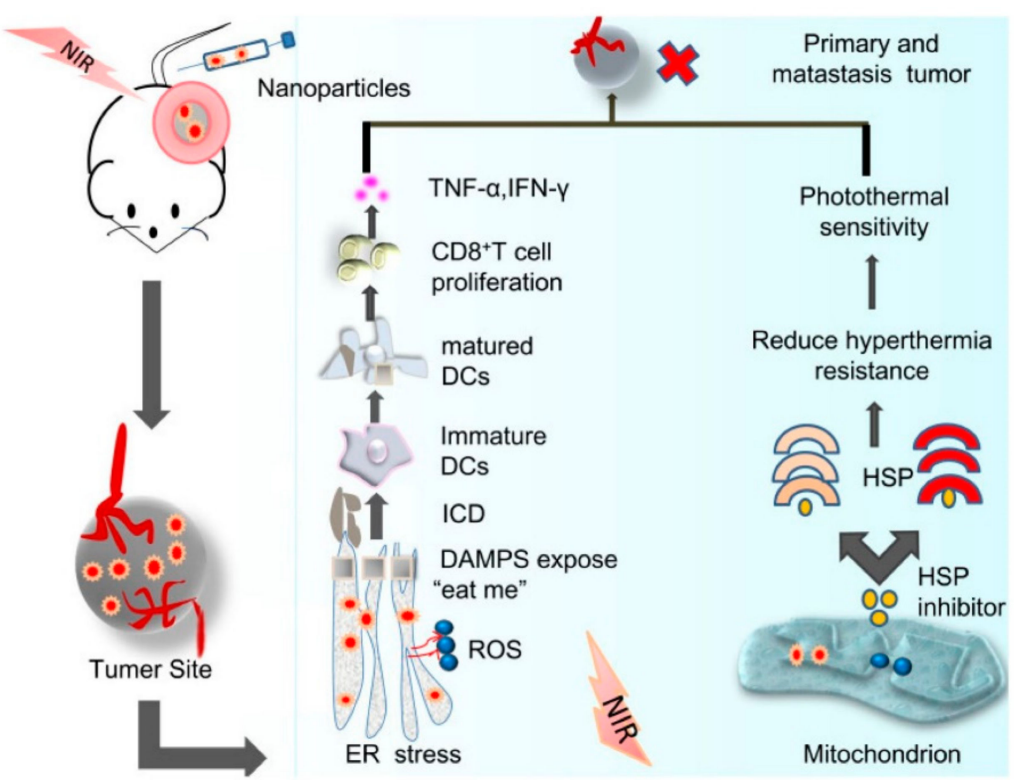

Figure 10. Possible pathways for immunogenic cell death due to the combination of PTT and PDT. Reprinted with permission from ref. [101]. Open Access Creative Common.

Translation of opto-magnetic nanocomposites presented in the current review in theranostic applications raise new challenges due to difficulty in controlling their physical characteristics such as size, shape, and uniform chemical composition. Variation of such physical factors leads to altered toxicological profiles in vivo, owing to uncertainty in pharmacodynamics, biodistribution, clearance, etc. It is well known that through exquisite control of surface coating of the nanocomposites, their physical properties along with toxicological aspects can be modulated.

Denis et al. observed that coating a dense dextran layer around the IONPs reduces their immunogenicity [18]. Yen et al. reported ultra-small NIR fluorophore-IONP hybrid nanoparticles showing minimal cytotoxicity [22]. Using histological analysis, Chen et al. probed the potential organ toxicity of a targeted fluorophore-conjugated IONP formulation following intravenous injection in mice bearing pancreatic tumor. Other than mild inflammation, no significant toxicity in normal organs was observed [23].

The importance of proper surface modification is extremely significant in the pursuit of a uniform formulation involving two different nanoparticle types. Wang et al. did not observe any general damage to normal organs following in vivo administration of magneto-fluorescent nanoparticles (silica-wrapped CdTe and IONPs, diameter $\sim 50 \mathrm{~nm}$ ) in a murine model of gastric cancer [42]. In a separate example, Wang et al. showed CdSe QDs and IONPs within liposomal coating makes the resulting nanocomposites non-toxic [44].

From a clinical trial perspective, significant efforts have been made for the translation of pre-clinical laboratory work to real-life clinical application and their commercialization of IONPs due to low toxicity. For example, Ferumoxytol was first approved by FDA as an iron supplement to treat anemia (iron deficiency) in adult patients with chronic kidney diseases. This has now been widely utilized as "off label" nanosuspension for vascular imaging, detection of stem cell transplantation, and cancer imaging purposes [102]. Recently, we have reported commercially available IONPs with their trade names and current stages of clinical application on specific diseases [103]. During the literature search, we found that some of the IONPs showed better results, whereas others were withdrawn from pre-clinical and clinical studies due to their toxicity.

NANOM was the first-in-man (FIM) trial to assess the safety and efficacy of silicagold (Nano group) and silica-iron-gold (Ferro group) nanoparticles containing IONPs completed recently for plaque management in atherosclerosis (ClinicalTrials.gov, Identifier: NCT01270139) [104]. A total of 180 patients received either Nano group $(n=60)$ as a patch in transplanted stem cells onto the cardiac artery or, Ferro group $(n=60)$ with CD68 
targeted micro-bubbles and stem cells using a magnetic navigation system (magnetic field of 0.08 Tesla) verses stent implantation $(n=60)$. The nanocomposites were activated with NIR laser (wavelength: $821 \mathrm{~nm}$, power density: 35-44 W/ $\mathrm{cm}^{2}$ ) for $7 \mathrm{~min}$ of exposure. The Nano-group was observed to be safe in clinical practice associated with significant regression of coronary atherosclerosis as evaluated by the total atheroma volume (TAV) at the end of 12 months. While the Nano-group was considered safe, the Ferro-group, in comparison, showed toxic effects with a major adverse cardiovascular event (MACE).

Signs of nanotoxicity of the iron-bearing nanocomposites could be due to their underlying cytotoxic effects, such as the generation of reactive oxygen species $[105,106]$, impairment of mitochondrial function, gene alteration, inflammation, chromosome condensation, and DNA damage [107]. Mahmoudi et al. in 2011 showed that the surface charge of the IONPs dictates the alteration of a number of gene expression patterns [106]. The presence of -COOH groups on IONPs was responsible for altering genes associated with cell proliferative responses. However, such gene alteration was subject to a specific cell type, indicating that nanoparticles with specific functional groups can play a significant role in defining the suitable pathways of nanoparticle toxicity. Additionally, the concentration of IONPs in the nanocomposite needs to be considered as a higher concentration of IONPs can cause irreversible DNA damage. $\mathrm{pH}$ can play an important role in controlling the nature (shapes, sizes, and zeta potential) of IONPs cores during their fabrication [108]. However, in the context of this review article on in vivo biomedical applications, the $\mathrm{pH}$ of a cellular system can also influence the formation of iron ions $\left(\mathrm{Fe}^{2+}\right)$ which are responsible for Fenton reaction and additional oxidative stress, especially in tumor sites where the $\mathrm{pH}$ is mostly acidic. The variation of shapes and sizes of IONPs core with optical probes may have an influence on the cellular diffusion hence the formation of iron ions $\left(\mathrm{Fe}^{2+}\right)$ in the tumor sites.

\section{Conclusions and Future Perspectives}

Detection of diseases and their cure using nanomedicine is an emerging trend in the area of nanotechnology, nano-biotechnology, and medicine. In this context, we have used one of the most applicable magnetic nanoparticles based on iron oxides (IONPs) and collected up-to-date literature information where IONPs have been conjugated with various optical probes. In this review, we have systematically classified all available optical probes from molecule-based probes (Class 1) to various optical nanoparticles (Classes 2 to 6) having fluorescence, plasmonic and up-conversion properties for especially focusing only on in vivo studies for biomedical applications. Classical molecule-based optical probes labeled as class 1 are well-known for bio-imaging, and several such probes are commercially available in spite of their limitation due to photobleaching and low quantum yield. Attaching them to IONPs overcomes such limitations due to their bimodal imaging (MRI and fluorescence) and multimodal therapeutic (PTT, PDT, and MHT) effects. Similarly, optical nanoparticle probes conjugated with IONPs create a range of opto-magnetic nanocomposites and their application in in vivo biomedical studies due to their multimodal imaging ability (MRI, CT, thermal, and fluorescence imaging) and multimodal therapeutic effects (in MHT, PTT, and PDT). Due to the toxicity of most of the semiconductor quantum dot nanoparticles (class 2), we have reviewed relatively non-toxic carbon-based nanoparticles (class 3 ) for in vivo biomedical applications. Among class 3 optical probes, CQD are reported to be promising nanomaterials due to their ultra-small sizes and fluorescence properties. The latest developments on up-conversion nanoparticles in conjugation with IONPs showed interesting fluorescence images where excitation was carried out using NIR laser light, having the advantage of high human tissue penetration depths. Similarly, we have identified the importance of plasmonic nanoparticles conjugated with IONPs for efficient multimodal diagnostic platforms such as CT and thermal imaging along with MRI. However, due to the toxicity issues associated with several optical probes, clinical applications and commercialization steps are a huge challenge; therefore, very little progress has been made in translating in vivo research to clinical trials. Finally, due to the multi- 
modal therapeutic and diagnostic properties of opto-magnetic nanocomposites, they have huge potential as future nanomedicines, especially by selecting already commercialized IONPs in conjugation with clinically approved commercial optical dyes such as Indocyanine Green (ICG), etc. This review will immensely contribute to nano-biotechnology and nanomedicine communities due to access to up-to-date information of various classes of optical probes in conjugation with IONPs in the latest developments in in vivo studies at the pre-clinical stage.

Author Contributions: The idea came from T.S. and I.R. along with equal contribution on abstract, introduction, conclusions, and editing the manuscript; I.R. also contributed to drafting the section on class 1 in Section 2; N.L. collected and wrote most of the parts on classes 2-6 in Section 2; S.S. and P. contributed to sections on class 5 in Section 2 along with partial support on Section 3. A.K.V. has partly contributed to Section 3. T.S. has organized the whole manuscript, proof-read and assembled it as a single article. All authors have read and agreed to the published version of the manuscript.

Funding: The work is funded by UK India Education Research Initiative (UKIERI), grant number IND/Cont/G 16-17/62.

Institutional Review Board Statement: Not Applicable.

Informed Consent Statement: Not Applicable.

Data Availability Statement: Not Applicable.

Acknowledgments: Authors sincerely acknowledge funding body UKIERI-UGC Joint Research Program (UKIERI III) for financial support. S.S. and Parul thank UGC-CSIR for partial funding of their PhD studies. N.L. also thanks UKIERI for partial funding.

Conflicts of Interest: The authors declare no conflict of interest.

\section{References}

1. Chen, G.; Roy, I.; Yang, C.; Prasad, P.N. Nanochemistry and Nanomedicine for Nanoparticle-based Diagnostics and Therapy. Chem. Rev. 2016, 116, 2826-2885. [CrossRef] [PubMed]

2. Cherukula, K.; Lekshmi, K.M.; Uthaman, S.; Cho, K.; Cho, C.-S.; Park, I.-K. Multifunctional Inorganic Nanoparticles: Recent Progress in Thermal Therapy and Imaging. Nanomaterials 2016, 6, 76. [CrossRef]

3. Biffi, S.; Voltan, R.; Rampazzo, E.; Prodi, L.; Zauli, G.; Secchiero, P. Applications of nanoparticles in cancer medicine and beyond: Optical and multimodal in vivo imaging, tissue targeting and drug delivery. Expert. Opin. Drug Deliv. 2015, 12, 1837-1849. [CrossRef]

4. Nguyen, K.T.; Zhao, Y. Engineered Hybrid Nanoparticles for On-Demand Diagnostics and Therapeutics. Acc. Chem. Res. 2015, 48, 3016-3025. [CrossRef]

5. Gadag, S.; Sinha, S.; Nayak, Y.; Garg, S.; Nayak, U.Y. Combination Therapy and Nanoparticulate Systems: Smart Approaches for the Effective Treatment of Breast Cancer. Pharmaceutics 2020, 12, 524. [CrossRef]

6. Decuzzi, P.; Peer, D.; Di Mascolo, D.; Palange, A.L.; Manghnani, P.N.; Moghimi, S.M.; Farhangrazi, Z.S.; A Howard, K.; Rosenblum, D.; Liang, T.; et al. Roadmap on nanomedicine. Nanotechnology 2021, 32, 012001. [CrossRef] [PubMed]

7. Israel, L.L.; Galstyan, A.; Holler, E.; Ljubimova, J.Y. Magnetic iron oxide nanoparticles for imaging, targeting and treatment of primary and metastatic tumors of the brain. J. Control. Release 2020, 320, 45-62. [CrossRef]

8. Lee, N.; Yoo, D.; Ling, D.; Cho, M.H.; Hyeon, T.; Cheon, J. Iron Oxide Based Nanoparticles for Multimodal Imaging and Magnetoresponsive Therapy. Chem. Rev. 2015, 115, 10637-10689. [CrossRef] [PubMed]

9. Hu, Y.; Mignani, S.; Majoral, J.-P.; Shen, M.; Shi, X. Construction of iron oxide nanoparticle-based hybrid platforms for tumor imaging and therapy. Chem. Soc. Rev. 2018, 47, 1874-1900. [CrossRef]

10. Estelrich, J.; Busquets, M.A. Iron Oxide Nanoparticles in Photothermal Therapy. Molecules 2018, 23, 1567. [CrossRef]

11. Gleich, B.; Weizenecker, J. Tomographic imaging using the nonlinear response of magnetic particles. Nat. Cell Biol. 2005, 435, 1214-1217. [CrossRef]

12. Jamieson, T.; Bakhshi, R.; Petrova, D.; Pocock, R.; Imani, M.; Seifalian, A.M. Biological applications of quantum dots. Biomaterials 2007, 28, 4717-4732. [CrossRef]

13. Van Dam, G.M.; Themelis, G.; A Crane, L.M.; Harlaar, N.J.; Pleijhuis, R.G.; Kelder, W.; Sarantopoulos, A.; De Jong, J.S.; Arts, H.J.G.; Van Der Zee, A.G.J.; et al. Intraoperative tumor-specific fluorescence imaging in ovarian cancer by folate receptor- $\alpha$ targeting: First in-human results. Nat. Med. 2011, 17, 1315-1319. [CrossRef] [PubMed]

14. Eyüpoglu, I.Y.; Hore, N.; Fan, Z.; Buslei, R.; Merkel, A.; Buchfelder, M.; Savaskan, N.E. Intraoperative vascular DIVA surgery reveals angiogenic hotspots in tumor zones of malignant gliomas. Sci. Rep. 2015, 5, 7958. [CrossRef] [PubMed] 
15. Belykh, E.; Martirosyan, N.L.; Yagmurlu, K.; Miller, E.J.; Eschbacher, J.M.; Izadyyazdanabadi, M.; Bardonova, L.A.; Byvaltsev, V.A.; Nakaji, P.; Preul, M.C. Intraoperative Fluorescence Imaging for Personalized Brain Tumor Resection: Current State and Future Directions. Front. Surg. 2016, 3, 55. [CrossRef]

16. Josephson, L.; Kircher, M.F.; Mahmood, U.; Tang, Y.; Weissleder, R. Near-Infrared Fluorescent Nanoparticles as Combined MR/Optical Imaging Probes. Bioconjugate Chem. 2002, 13, 554-560. [CrossRef] [PubMed]

17. Kircher, M.F.; Mahmood, U.; King, R.S.; Weissleder, R.; Josephson, L. A multimodal nanoparticle for preoperative magnetic resonance imaging and intraoperative optical brain tumor delineation. Cancer Res. 2003, 63, 8122-8125.

18. Denis, M.C.; Mahmood, U.; Benoist, C.; Mathis, D.; Weissleder, R. Imaging inflammation of the pancreatic islets in type 1 diabetes. Proc. Natl. Acad. Sci. USA 2004, 101, 12634-12639. [CrossRef]

19. Jaffer, F.A.; Nahrendorf, M.; Sosnovik, D.; Kelly, K.A.; Aikawa, E.; Weissleder, R. Cellular Imaging of Inflammation in Atherosclerosis Using Magnetofluorescent Nanomaterials. Mol. Imaging 2006, 5, 85-92. [CrossRef]

20. Sosnovik, D.E.; Schellenberger, E.A.; Nahrendorf, M.; Novikov, M.S.; Matsui, T.; Dai, G.; Reynolds, F.; Grazette, L.; Rosenzweig, A.; Weissleder, R.; et al. Magnetic resonance imaging of cardiomyocyte apoptosis with a novel magneto-optical nanoparticle. Magn. Reson. Med. 2005, 54, 718-724. [CrossRef]

21. Foy, S.P.; Manthe, R.L.; Foy, S.T.; Dimitrijevic, S.; Krishnamurthy, N.; Labhasetwar, V. Optical Imaging and Magnetic Field Targeting of Magnetic Nanoparticles in Tumors. Acs Nano 2010, 4, 5217-5224. [CrossRef]

22. Yen, S.K.; Jańczewski, D.; Lakshmi, J.L.; Bin Dolmanan, S.; Tripathy, S.; Ho, V.H.B.; Vijayaragavan, V.; Hariharan, A.; Padmanabhan, P.; Bhakoo, K.K.; et al. Design and Synthesis of Polymer-Functionalized NIR Fluorescent Dyes-Magnetic Nanoparticles for Bioimaging. Acs Nano 2013, 7, 6796-6805. [CrossRef] [PubMed]

23. Chen, X.; Zhou, H.; Li, X.; Duan, N.; Hu, S.; Liu, Y.; Yue, Y.; Song, L.; Zhang, Y.; Li, D.; et al. Plectin-1 Targeted Dual-modality Nanoparticles for Pancreatic Cancer Imaging. EBioMedicine 2018, 30, 129-137. [CrossRef] [PubMed]

24. Key, J.; Dhawan, D.; Cooper, C.L.; Knapp, D.W.; Kim, K.; Kwon, I.C.; Choi, K.; Park, K.; Decuzzi, P.; Leary, J.F. Multicomponent, peptide-targeted glycol chitosan nanoparticles containing ferrimagnetic iron oxide nanocubes for bladder cancer multimodal imaging. Int. J. Nanomed. 2016, 11, 4141-4155. [CrossRef]

25. Hsu, J.C.; Naha, P.C.; Lau, K.C.; Chhour, P.; Hastings, R.; Moon, B.F.; Stein, J.M.; Witschey, W.R.T.; McDonald, E.S.; Maidment, A.D.A.; et al. An all-in-one nanoparticle (AION) contrast agent for breast cancer screening with DEM-CT-MRI-NIRF imaging. Nanoscale 2018, 10, 17236-17248. [CrossRef] [PubMed]

26. Arami, H.; Khandhar, A.P.; Tomitaka, A.; Yu, E.; Goodwill, P.W.; Conolly, S.M.; Krishnan, K.M. In vivo multimodal magnetic particle imaging (MPI) with tailored magneto/optical contrast agents. Biomaterials 2015, 52, 251-261. [CrossRef]

27. Li, Y.; Xu, D.; Chan, H.-N.; Poon, C.-Y.; Ho, S.-L.; Li, H.-W.; Wong, M.S. Dual-Modal NIR-Fluorophore Conjugated Magnetic Nanoparticle for Imaging Amyloid- $\beta$ Species In Vivo. Small 2018, 14, e1800901. [CrossRef]

28. Janßen, H.C.; Warwas, D.P.; Dahlhaus, D.; Meißner, J.; Taptimthong, P.; Kietzmann, M.; Behrens, P.; Reifenrath, J.; Angrisani, $\mathrm{N}$. In vitro and in vivo accumulation of magnetic nanoporous silica nanoparticles on implant materials with different magnetic properties. J. Nanobiotechnol. 2018, 16, 96. [CrossRef]

29. Roy, I.; Ohulchanskyy, T.Y.; Pudavar, H.E.; Bergey, E.J.; Oseroff, A.R.; Morgan, J.; Dougherty, T.J.; Prasad, P.N. Ceramic-Based Nanoparticles Entrapping Water-Insoluble Photosensitizing Anticancer Drugs: A Novel Drug-Carrier System for Photodynamic Therapy. J. Am. Chem. Soc. 2003, 125, 7860-7865. [CrossRef]

30. Ethirajan, M.; Chen, Y.; Joshi, P.; Pandey, R.K. The role of porphyrin chemistry in tumor imaging and photodynamic therapy. Chem. Soc. Rev. 2011, 40, 340-362. [CrossRef]

31. Lo, P.-C.; Rodríguez-Morgade, M.S.; Pandey, R.K.; Ng, D.K.P.; Torres, T.; Dumoulin, F. The unique features and promises of phthalocyanines as advanced photosensitisers for photodynamic therapy of cancer. Chem. Soc. Rev. 2020, 49, 1041-1056. [CrossRef]

32. Kopelman, R.; Koo, Y.-E.L.; Philbert, M.; Moffat, B.A.; Reddy, G.R.; McConville, P.; Hall, D.E.; Chenevert, T.L.; Bhojani, M.S.; Buck, S.M.; et al. Multifunctional nanoparticle platforms for in vivo MRI enhancement and photodynamic therapy of a rat brain cancer. J. Magn. Magn. Mater. 2005, 293, 404-410. [CrossRef]

33. Sun, Y.; Chen, Z.-L.; Yang, X.-X.; Huang, P.; Zhou, X.-P.; Du, X.-X. Magnetic chitosan nanoparticles as a drug delivery system for targeting photodynamic therapy. Nanotechnology 2009, 20, 135102. [CrossRef]

34. Yin, T.; Huang, P.; Gao, G.; Shapter, J.G.; Shen, Y.; Sun, R.; Yue, C.; Zhang, C.; Liu, Y.; Zhou, S.; et al. Superparamagnetic Fe3O4-PEG2K-FA@Ce6 Nanoprobes for in Vivo Dual-mode Imaging and Targeted Photodynamic Therapy. Sci. Rep. 2016, 6, 36187. [CrossRef]

35. Di Corato, R.; Béalle, G.; Kolosnjaj-Tabi, J.; Espinosa, A.; Clement, O.; Silva, A.K.; Menager, C.; Wilhelm, C. Combining magnetic hyperthermia and photodynamic therapy for tumor ablation with photoresponsive magnetic liposomes. Acs Nano 2015, 9, 2904-2916. [CrossRef] [PubMed]

36. Kim, K.S.; Lee, J.Y.; Matsuda, S.; Hideshima, S.; Mori, Y.; Osaka, T.; Na, K. Stimuli-responsive magnetic nanoparticles for tumor-targeted bimodal imaging and photodynamic/hyperthermia combination therapy. Nanoscale 2016, 8, 11625-11634. [CrossRef] [PubMed]

37. Song, S.; Shen, H.; Yang, T.; Wang, L.; Fu, H.; Chen, H.; Zhang, Z. Indocyanine Green Loaded Magnetic Carbon Nanoparticles for Near Infrared Fluorescence/Magnetic Resonance Dual-Modal Imaging and Photothermal Therapy of Tumor. Acs Appl. Mater. Interfaces 2017, 9, 9484-9495. [CrossRef] 
38. Sharma, S.; Parul; Lamichhane, N.; Sen, T.; Roy, I. Iron oxide nanoparticles conjugated with organic optical probes for In-vivo biomedical applications. Nanomedicine 2021. under review.

39. Prasad, P.N. Introduction to Biophotonics; John Wiley and Sons: Hoboken, NJ, USA, 2003; pp. 528-531.

40. Shi, D.; Cho, H.S.; Chen, Y.; Xu, H.; Gu, H.; Lian, J.; Wang, W.; Liu, G.; Huth, C.; Wang, L.; et al. Fluorescent PolystyreneFe3O4Composite Nanospheres for In Vivo Imaging and Hyperthermia. Adv. Mater. 2009, 21, 2170-2173. [CrossRef]

41. Chen, O.; Riedemann, L.; Etoc, F.; Herrmann, H.; Coppey, M.; Barch, M.; Farrar, C.T.; Zhao, J.; Bruns, O.T.; Wei, H.; et al. Magneto-fluorescent core-shell supernanoparticles. Nat. Commun. 2014, 5, 1-8. [CrossRef]

42. Wang, K.; Ruan, J.; Qian, Q.; Song, H.; Bao, C.; Zhang, X.; Kong, Y.; Zhang, C.; Hu, G.; Ni, J.; et al. BRCAA1 monoclonal antibody conjugated fluorescent magnetic nanoparticles for in vivo targeted magnetofluorescent imaging of gastric cancer. J. Nanobiotechnol. 2011, 9, 23. [CrossRef] [PubMed]

43. Ruan, J.; Ji, J.; Song, H.; Qian, Q.; Wang, K.; Wang, C.; Cui, D. Fluorescent magnetic nanoparticle-labeled mesenchymal stem cells for targeted imaging and hyperthermia therapy of in vivo gastric cancer. Nanoscale Res. Lett. 2012, 7, 309. [CrossRef]

44. Wang, F.F.; Chen, Z.P.; Zhu, L. cRGD-conjugated magnetic-fluorescent liposomes for targeted dual-modality imaging of bone metastasis from prostate cancer. J. Liposome Res. 2015, 25, 89-100. [CrossRef] [PubMed]

45. Liu, Y.; Hughes, T.C.; Muir, B.W.; Waddington, L.J.; Gengenbach, T.R.; Easton, C.D.; Hinton, T.M.; Moffat, B.A.; Hao, X.; Qiu, J. Water-dispersible magnetic carbon nanotubes as T2-weighted MRI contrast agents. Biomaterials 2014, 35, 378-386. [CrossRef]

46. Al Faraj, A.; Shaik, A.P.; Shaik, A.S. Magnetic single-walled carbon nanotubes as efficient drug delivery nanocarriers in breast cancer murine model: Noninvasive monitoring using diffusion-weighted magnetic resonance imaging as sensitive imaging biomarker. Int. J. Nanomedicine 2015, 10, 157. [CrossRef] [PubMed]

47. Das, B.; Dadhich, P.; Pal, P.; Srivas, P.K.; Bankoti, K.; Dhara, S. Carbon nanodots from date molasses: New nanolights for the in vitro scavenging of reactive oxygen species. J. Mater. Chem. B 2014, 2, 6839-6847. [CrossRef]

48. Liu, X.; Jiang, H.; Ye, J.; Zhao, C.; Gao, S.; Wu, C.; Li, C.; Li, J.; Wang, X. Nitrogen-Doped Carbon Quantum Dot Stabilized Magnetic Iron Oxide Nanoprobe for Fluorescence, Magnetic Resonance, and Computed Tomography Triple-Modal In Vivo Bioimaging. Adv. Funct. Mater. 2016, 26, 8694-8706. [CrossRef]

49. Das, B.; Girigoswami, A.; Dutta, A.; Pal, P.; Dutta, J.; Dadhich, P.; Srivas, P.K.; Dhara, S. Carbon Nanodots Doped Superparamagnetic Iron Oxide Nanoparticles for Multimodal Bioimaging and Osteochondral Tissue Regeneration via External Magnetic Actuation. Acs Biomater. Sci. Eng. 2019, 5, 3549-3560. [CrossRef] [PubMed]

50. Shi, X.; Gong, H.; Li, Y.; Wang, C.; Cheng, L.; Liu, Z. Graphene-based magnetic plasmonic nanocomposite for dual bioimaging and photothermal therapy. Biomaterials 2013, 34, 4786-4793. [CrossRef] [PubMed]

51. Ma, X.; Tao, H.; Yang, K.; Feng, L.; Cheng, L.; Shi, X.; Li, Y.; Guo, L.; Liu, Z. A functionalized graphene oxide-iron oxide nanocomposite for magnetically targeted drug delivery, photothermal therapy, and magnetic resonance imaging. Nano Res. 2012, 5, 199-212. [CrossRef]

52. Yang, D.; Li, C.; Lin, J. Multimodal cancer imaging using lanthanide-based upconversion nanoparticles. Nanomedicine 2015, 10, 2573-2591. [CrossRef]

53. Luo, Y.; Du, S.; Zhang, W.; Liao, Z.; Zuo, F.; Yang, S.-T. Core@shell Fe3O4@Mn2+-doped NaYF4:Yb/Tm nanoparticles for triple-modality T1/T2-weighted MRI and NIR-to-NIR upconversion luminescence imaging agents. Rsc Adv. 2017, 7, 37929-37937. [CrossRef]

54. Zhang, F.; Braun, G.B.; Pallaoro, A.; Zhang, Y.; Shi, Y.; Cui, D.; Moskovits, M.; Zhao, D.; Stucky, G.D. Mesoporous Multifunctional Upconversion Luminescent and Magnetic "Nanorattle" Materials for Targeted Chemotherapy. Nano Lett. 2012, 12 , 61-67. [CrossRef] [PubMed]

55. Cheng, L.; Yang, K.; Li, Y.; Chen, J.; Wang, C.; Shao, M.; Lee, S.-T.; Liu, Z. Facile Preparation of Multifunctional Upconversion Nanoprobes for Multimodal Imaging and Dual-Targeted Photothermal Therapy. Angew. Chem. Int. Ed. 2011, 50, 7385-7390. [CrossRef]

56. Cheng, L.; Yang, K.; Li, Y.; Zeng, X.; Shao, M.; Lee, S.-T.; Liu, Z. Multifunctional nanoparticles for upconversion luminescence/MR multimodal imaging and magnetically targeted photothermal therapy. Biomaterials 2012, 33, 2215-2222. [CrossRef] [PubMed]

57. Xu, H.; Cheng, L.; Wang, C.; Ma, X.; Li, Y.; Liu, Z. Polymer encapsulated upconversion nanoparticle/iron oxide nanocomposites for multimodal imaging and magnetic targeted drug delivery. Biomaterials 2011, 32, 9364-9373. [CrossRef]

58. Riley, R.S.; Day, E.S. Gold nanoparticle-mediated photothermal therapy: Applications and opportunities for multimodal cancer treatment. Wiley Interdiscip. Rev. Nanomed. Nanobiotechnol. 2017, 9, e1449. [CrossRef] [PubMed]

59. Silva, S.M.; Tavallaie, R.; Sandiford, L.; Tilley, R.D.; Gooding, J.J. Gold coated magnetic nanoparticles: From preparation to surface modification for analytical and biomedical applications. Chem. Commun. 2016, 52, 7528-7540. [CrossRef]

60. Xu, Z.; Hou, Y.; Sun, S. Magnetic core/shell Fe3O4/Au and Fe3O4/Au/Ag nanoparticles with tunable plasmonic properties. J. Am. Chem. Soc. 2007, 129, 8698-8699. [CrossRef]

61. Carpenter, E.E.; Sangregorio, C.; O'Connor, C.J. Effects of shell thickness on blocking temperature of nanocomposites of metal particles with gold shells. IEEE Trans. Magn. 1999, 35, 3496-3498. [CrossRef]

62. Lyon, J.L.; Fleming, D.A.; Stone, M.B.; Schiffer, P.; Williams, M.E. Synthesis of Fe Oxide Core/Au Shell Nanoparticles by Iterative Hydroxylamine Seeding. Nano Lett. 2004, 4, 719-723. [CrossRef]

63. A Larson, T.; Bankson, J.; Aaron, J.; Sokolov, K. Hybrid plasmonic magnetic nanoparticles as molecular specific agents for MRI/optical imaging and photothermal therapy of cancer cells. Nanotechnology 2007, 18, 325101. [CrossRef] 
64. Kim, D.; Yu, M.K.; Lee, T.S.; Park, J.J.; Jeong, Y.Y.; Jon, S. Amphiphilic polymer-coated hybrid nanoparticles as CT/MRI dual contrast agents. Nanotechnology 2011, 22, 155101. [CrossRef] [PubMed]

65. Cai, H.; Li, K.; Shen, M.; Wen, S.; Luo, Y.; Peng, C.; Zhang, G.; Shi, X. Facile assembly of Fe3O4@Au nanocomposite particles for dual mode magnetic resonance and computed tomography imaging applications. J. Mater. Chem. 2012, 22, 15110-15120. [CrossRef]

66. Li, W.-P.; Liao, P.-Y.; Su, C.-H.; Yeh, C.-S. Formation of Oligonucleotide-Gated Silica Shell-Coated Fe3O4-Au Core-Shell Nanotrisoctahedra for Magnetically Targeted and Near-Infrared Light-Responsive Theranostic Platform. J. Am. Chem. Soc. 2014, 136, 10062-10075. [CrossRef]

67. Espinosa, A.; Bugnet, M.; Radtke, G.; Neveu, S.; Botton, G.A.; Wilhelm, C.; Abou-Hassan, A. Can magneto-plasmonic nanohybrids efficiently combine photothermia with magnetic hyperthermia? Nanoscale 2015, 7, 18872-18877. [CrossRef]

68. Lartigue, L.; Hugounenq, P.; Alloyeau, D.; Clarke, S.P.; Lévy, M.; Bacri, J.-C.; Bazzi, R.; Brougham, D.F.; Wilhelm, C.; Gazeau, F. Cooperative Organization in Iron Oxide Multi-Core Nanoparticles Potentiates Their Efficiency as Heating Mediators and MRI Contrast Agents. ACS Nano 2012, 6, 10935-10949. [CrossRef] [PubMed]

69. Li, J.; Hu, Y.; Yang, J.; Wei, P.; Sun, W.; Shen, M.; Zhang, G.; Shi, X. Hyaluronic acid-modified Fe3O4@Au core/shell nanostars for multimodal imaging and photothermal therapy of tumors. Biomaterials 2015, 38, 10-21. [CrossRef]

70. Zhao, J.; Vykoukal, J.; Abdelsalam, M.; Recio-Boiles, A.; Huang, Q.; Qiao, Y.; Singhana, B.; Wallace, M.; Avritscher, R.; Melancon, M.P. Stem cell-mediated delivery of SPIO-loaded gold nanoparticles for the theranosis of liver injury and hepatocellular carcinoma. Nanotechnology 2014, 25, 405101. [CrossRef] [PubMed]

71. Qiao, Y.; Gumin, J.; MacLellan, C.J.; Gao, F.; Bouchard, R.; Lang, F.F.; Stafford, R.J.; Melancon, M.P. Magnetic resonance and photoacoustic imaging of brain tumor mediated by mesenchymal stem cell labeled with multifunctional nanoparticle introduced via carotid artery injection. Nanotechnology 2018, 29, 165101. [CrossRef]

72. Mirrahimi, M.; Hosseini, V.; Kamrava, S.K.; Attaran, N.; Beik, J.; Kooranifar, S.; Ghaznavi, H.; Shakeri-Zadeh, A. Selective heat generation in cancer cells using a combination of $808 \mathrm{~nm}$ laser irradiation and the folate-conjugated Fe2O3@Au nanocomplex. Artif. Cellsnanomedicinebiotechnol. 2018, 46, 241-253. [CrossRef] [PubMed]

73. Abed, Z.; Beik, J.; Laurent, S.; Eslahi, N.; Khani, T.; Davani, E.S.; Ghaznavi, H.; Shakeri-Zadeh, A. Iron oxide-gold core-shell nano-theranostic for magnetically targeted photothermal therapy under magnetic resonance imaging guidance. J. Cancer Res. Clin. Oncol. 2019, 145, 1213-1219. [CrossRef] [PubMed]

74. Wang, M.; Liang, Y.; Zhang, Z.; Ren, G.; Liu, Y.; Wu, S.; Shen, J. Ag@ Fe3O4@ C nanoparticles for multi-modal imaging-guided chemo-photothermal synergistic targeting for cancer therapy. Anal. Chim. Acta. 2019, 1086, 122-132. [CrossRef]

75. Curcio, A.; Silva, A.K.A.; Cabana, S.; Espinosa, A.; Baptiste, B.; Menguy, N.; Wilhelm, C.; Abou-Hassan, A. Iron Oxide Nanoflowers @ CuS Hybrids for Cancer Tri-Therapy: Interplay of Photothermal Therapy, Magnetic Hyperthermia and Photodynamic Therapy. Theranostics 2019, 9, 1288-1302. [CrossRef]

76. Angelé-Martínez, C.; Nguyen, K.V.T.; Ameer, F.S.; Anker, J.N.; Brumaghim, J.L. Reactive oxygen species generation by copper(II) oxide nanoparticles determined by DNA damage assays and EPR spectroscopy. Nanotoxicology 2017, 11, 278-288. [CrossRef]

77. Cabrera, D.; Camarero, J.; Ortega, D.; Teran, F.J. Influence of the aggregation, concentration, and viscosity on the nanomagnetism of iron oxide nanoparticle colloids for magnetic hyperthermia. J. Nanoparticle Res. 2015, 17, 1-6. [CrossRef]

78. Zhu, X.; Huang, H.; Zhang, Y.; Zhang, H.; Hou, L.; Zhang, Z. Cit/CuS@ Fe3O4-based and enzyme-responsive magnetic nanoparticles for tumor chemotherapy, photothermal, and photodynamic therapy. J. Biomater. Appl. 2017, 31, 1010-1025. [CrossRef] [PubMed]

79. Kim, D.-H.; Li, W.; Chen, J.; Zhang, Z.; Green, R.M.; Huang, S.; Larson, A.C. Multimodal Imaging of Nanocomposite Microspheres for Transcatheter Intra-Arterial Drug Delivery to Liver Tumors. Sci. Rep. 2016, 6, 29653. [CrossRef] [PubMed]

80. Yan, D.; Liu, X.; Deng, G.; Yuan, H.; Wang, Q.; Zhang, L.; Lu, J. Facile assembling of novel polypyrrole nanocomposites theranostic agent for magnetic resonance and computed tomography imaging guided efficient photothermal ablation of tumors. J. Colloid Interface Sci. 2018, 530, 547-555. [CrossRef]

81. Li, Q.; Zhang, L.; Bai, L.; Zhang, Z.; Zhu, J.; Zhou, N.; Cheng, Z.; Zhu, X. Multistimuli-responsive hybrid nanoparticles with magnetic core and thermoresponsive fluorescence-labeled shell via surface-initiated RAFT polymerization. Soft Matter 2011, 7, 6958-6966. [CrossRef]

82. Yan, K.; Li, H.; Li, P.; Zhu, H.; Shen, J.; Yi, C.; Wu, S.; Yeung, K.W.; Xu, Z.; Xu, H.; et al. Self-assembled magnetic fluorescent polymeric micelles for magnetic resonance and optical imaging. Biomaterials 2014, 35, 344-355. [CrossRef] [PubMed]

83. Li, B.; Gong, T.; Xu, N.; Cui, F.; Yuan, B.; Yuan, Q.; Sun, H.; Wang, L.; Liu, J. Improved Stability and Photothermal Performance of Polydopamine-Modified Fe $3 \mathrm{O} 4$ Nanocomposites for Highly Efficient Magnetic Resonance Imaging-Guided Photothermal Therapy. Small 2020, 16, e2003969. [CrossRef]

84. Wang, X.; Tu, M.; Yan, K.; Li, P.; Pang, L.; Gong, Y.; Li, Q.; Liu, R.; Xu, Z.; Xu, H.; et al. Trifunctional Polymeric Nanocomposites Incorporated with Fe3O4/Iodine-Containing Rare Earth Complex for Computed X-ray Tomography, Magnetic Resonance, and Optical Imaging. Acs Appl. Mater. Interfaces 2015, 7, 24523-24532. [CrossRef]

85. Yan, K.; Li, H.; Wang, X.; Yi, C.; Zhang, Q.; Xu, Z.; Xu, H.; Whittaker, A.K. Self-assembled magnetic luminescent hybrid micelles containing rare earth Eu for dual-modality MR and optical imaging. J. Mater. Chem. B 2013, 2, 546-555. [CrossRef] [PubMed] 
86. Valdiglesias, V.; Fernández-Bertólez, N.; Kiliç, G.; Costa, C.; Costa, S.; Fraga, S.; Bessa, M.J.; Pásaro, E.; Teixeira, J.P.; Laffon, B. Are iron oxide nanoparticles safe? Current knowledge and future perspectives. J. Trace Elem. Med. Biol. 2016, $38,53-63$. [CrossRef] [PubMed]

87. Vallabani, N.V.S.; Singh, S. Recent advances and future prospects of iron oxide nanoparticles in biomedicine and diagnostics. 3 Biotech. 2018, 8, 1-23. [CrossRef] [PubMed]

88. Fadeel, B.; Garcia-Bennett, A.E. Better safe than sorry: Understanding the toxicological properties of inorganic nanoparticles manufactured for biomedical applications. Adv. Drug Deliv. Rev. 2009, 62, 362-374. [CrossRef]

89. Patil, U.S.; Adireddy, S.; Jaiswal, A.; Mandava, S.H.; Lee, B.R.; Chrisey, D.B. In Vitro/In Vivo Toxicity Evaluation and Quantification of Iron Oxide Nanoparticles. Int. J. Mol. Sci. 2015, 16, 24417-24450. [CrossRef]

90. Malhotra, N.; Lee, J.-S.; Liman, R.A.D.; Ruallo, J.M.S.; Villaflores, O.B.; Ger, T.-R.; Hsiao, C.-D. Potential Toxicity of Iron Oxide Magnetic Nanoparticles: A Review. Molecules 2020, 25, 3159. [CrossRef]

91. Dissanayake, N.M.; Current, K.M.; Obare, S.O. Mutagenic Effects of Iron Oxide Nanoparticles on Biological Cells. Int. J. Mol. Sci. 2015, 16, 23482-23516. [CrossRef]

92. Sakulkhu, U.; Mahmoudi, M.; Maurizi, L.; Coullerez, G.; Hofmann-Amtenbrink, M.; Vries, M.; Motazacker, M.; Rezaee, F.; Hofmann, H. Significance of surface charge and shell material of superparamagnetic iron oxide nanoparticle (SPION) based core/shell nanoparticles on the composition of the protein corona. Biomater. Sci. 2014, 3, 265-278. [CrossRef] [PubMed]

93. Breskey, J.D.; Lacey, S.E.; Vesper, B.J.; Paradise, W.A.; Radosevich, J.A.; Colvard, M.D. Photodynamic Therapy: Occupational Hazards and Preventative Recommendations for Clinical Administration by Healthcare Providers. Photomed. Laser Surg. 2013, 31, 398-407. [CrossRef] [PubMed]

94. Rueda-Gensini, L.; Cifuentes, J.; Castellanos, M.C.; Puentes, P.R.; Serna, J.A.; Muñoz-Camargo, C.; Cruz, J.C. Tailoring Iron Oxide Nanoparticles for Efficient Cellular Internalization and Endosomal Escape. Nanomaterials 2020, 10, 1816. [CrossRef] [PubMed]

95. Yadav, M.; Niveria, K.; Sen, T.; Roy, I.; Verma, K.A. Underpinning non-apoptotic pathways by multifunctional nanoparticles for cancer therapy: Current \& future perspectives. Nanomedicine 2021, in press.

96. Rivolta, I.; Panariti, A.; Miserocchi, G. The effect of nanoparticle uptake on cellular behavior: Disrupting or enabling functions? Nanotechnol. Sci. Appl. 2012, 5, 87-100. [CrossRef]

97. Hirota, K.; Ter, H. Endocytosis of Particle Formulations by Macrophages and Its Application to Clinical Treatment. In Molecular Regulation of Endocytosis; IntechOpen: London, UK, 2012.

98. Sandvig, K.; Kavaliauskiene, S.; Skotland, T. Clathrin-independent endocytosis: An increasing degree of complexity. Histochem. Cell Biol. 2018, 150, 107-118. [CrossRef] [PubMed]

99. Knutson, M.D. Steap proteins: Implications for iron and copper metabolism. Nutr. Rev. 2007, 65, 335-340.

100. Zhu, J.; Xiong, Y.; Zhang, Y.; Wen, J.; Cai, N.; Cheng, K.; Liang, H.; Zhang, W. The Molecular Mechanisms of Regulating Oxidative Stress-Induced Ferroptosis and Therapeutic Strategy in Tumors. Oxidative Med. Cell. Longev. 2020, 2020, 1-14. [CrossRef]

101. Hou, Y.-J.; Yang, X.-X.; Liu, R.-Q.; Zhao, D.; Guo, C.-N.; Zhu, A.-C.; Wen, M.-N.; Liu, Z.; Qu, G.-F.; Meng, H.-X. Pathological Mechanism of Photodynamic Therapy and Photothermal Therapy Based on Nanoparticles. Int. J. Nanomed. 2020, 15, 6827-6838. [CrossRef]

102. Nejadnik, H.; Pandit, P.; Lenkov, O.; Lahiji, A.P.; Yerneni, K.; Daldrup-Link, H.E. Ferumoxytol Can Be Used for Quantitative Magnetic Particle Imaging of Transplanted Stem Cells. Mol. Imaging Biol. 2018, 21, 465-472. [CrossRef] [PubMed]

103. Lamichhane, N.; Sharifabad, M.E.; Hodgson, B.; Mercer, T.; Sen, T. Superparamagnetic iron oxide nanoparticles (SPIONs) as therapeutic and diagnostic agents. In Nanoparticle Therapeutics: Production Technologies, Types of Nanoparticles, and Regulatory Aspects; Kesharwani, P., Singh, K., Eds.; Elsevier: Oslo, Norway, 2021; in press.

104. Kharlamov, M.A.N.; Feinstein, J.A.; Cramer, J.A.; Boothroyd, J.A.; Shishkina, E.; Shur, V. Plasmonic photothermal therapy of atherosclerosis with nanoparticles: Long-term outcomes and safety in NANOM-FIM trial. Futur. Cardiol. 2017, 13, 345-363. [CrossRef] [PubMed]

105. Stroh, A.; Zimmer, C.; Gutzeit, C.; Jakstadt, M.; Marschinke, F.; Jung, T.; Pilgrimm, H.; Grune, T. Iron oxide particles for molecular magnetic resonance imaging cause transient oxidative stress in rat macrophages. Free. Radic. Biol. Med. 2004, 36, 976-984. [CrossRef] [PubMed]

106. Mahmoudi, M.; Laurent, S.; Shokrgozar, M.A.; Hosseinkhani, M. Toxicity Evaluations of Superparamagnetic Iron Oxide Nanoparticles: Cell “Vision" versus Physicochemical Properties of Nanoparticles. Acs Nano 2011, 5, 7263-7276. [CrossRef] [PubMed]

107. Mahmoudi, M.; Simchi, A.; Imani, M. Cytotoxicity of Uncoated and Polyvinyl Alcohol Coated Superparamagnetic Iron Oxide Nanoparticles. J. Phys. Chem. C 2009, 113, 9573-9580. [CrossRef]

108. Mahmoudi, M.; Sant, S.; Wang, B.; Laurent, S.; Sen, T. Superparamagnetic iron oxide nanoparticles (SPIONs): Development, surface modification and applications in chemotherapy. Adv. Drug Deliv. Rev. 2011, 63, 24-46. [CrossRef] [PubMed] 